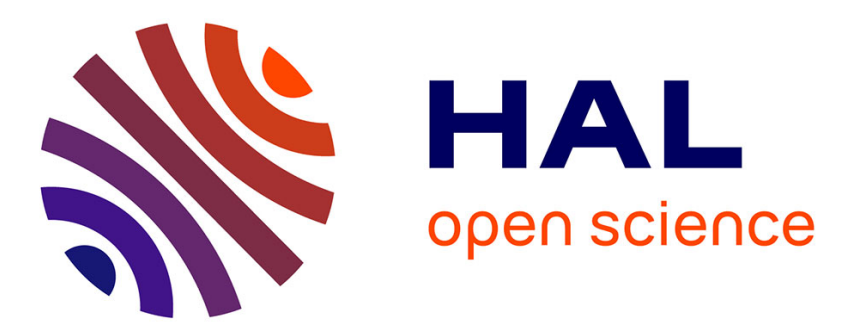

\title{
Prediction-Based Super Twisting Sliding Mode Load Frequency Control for Multi Area Interconnected Power Systems with State and Input Time Delays using Disturbance Observer
}

Ark Dev, Vincent Léchappé, Mrinal Kanti Sarkar

\section{To cite this version:}

Ark Dev, Vincent Léchappé, Mrinal Kanti Sarkar. Prediction-Based Super Twisting Sliding Mode Load Frequency Control for Multi Area Interconnected Power Systems with State and Input Time Delays using Disturbance Observer. International Journal of Control, 2019, 10.1080/00207179.2019.1673487 . hal-02302028

\section{HAL Id: hal-02302028 \\ https://hal.science/hal-02302028}

Submitted on 1 Oct 2019

HAL is a multi-disciplinary open access archive for the deposit and dissemination of scientific research documents, whether they are published or not. The documents may come from teaching and research institutions in France or abroad, or from public or private research centers.
L'archive ouverte pluridisciplinaire HAL, est destinée au dépôt et à la diffusion de documents scientifiques de niveau recherche, publiés ou non, émanant des établissements d'enseignement et de recherche français ou étrangers, des laboratoires publics ou privés. 


\title{
Prediction-Based Super Twisting Sliding Mode Load Frequency
}

Control for Multi Area Interconnected Power Systems with State and Input Time Delays using Disturbance Observer

\author{
Ark Deva ${ }^{\mathrm{a}}$, Vincent Léchappéb and Mrinal Kanti Sarkar*a \\ a Department of Electrical Engineering, National Institute of Technology Manipur, \\ Imphal, India \\ ${ }^{b}$ Univ Lyon, INSA Lyon, ECL, Université Claude Bernard Lyon 1, CNRS, Ampère, F- \\ 69621, Villeurbanne, France \\ *mks_ee@ieee.org
}




\title{
Prediction-Based Super Twisting Sliding Mode Load Frequency Control for Multi Area Interconnected Power Systems with State and Input Time Delays using Disturbance Observer
}

\begin{abstract}
A shift in paradigm from dedicated to open communication channels in power systems have made them prone to constant and time varying delays. This paper tackles a novel load frequency control (LFC) problem in the presence of constant and time varying delays in state and control input under load disturbances. The presence of time delays can deteriorate the performance of the controller or even destabilize the system. The above problem is addressed through a prediction-based super twisting sliding mode control (ST-SMC) using a state and disturbance observer. The proposed design achieves finite time convergence of frequency and tie line power deviation. The said design is validated under ramp and random step disturbance, with nonlinearities like generation rate constraints and governor deadband, with an integration of renewable energy and also with IEEE 39 bus power system. The closed loop stability is proven thanks to candidate Lyapunov function and verified by simulations.
\end{abstract}

Keywords: Delay system, disturbance observer, robust control, super twisting control, load frequency control, predictive-based control.

\section{Introduction}

Time delay is a common phenomenon in many engineering problems such as biological systems, chemical processes, communication networks, metallurgical processes, fluid transmission systems and network control systems (NCS). A system is said to be delayed in time when the rate of variation in system state depends on the past state (Zhong, 2006; Wu et al., 2010). Time delay systems (TDS) are often known as systems with aftereffect or deadtime or hereditary systems. Multi area interconnected power systems are classic example of NCS.

Ever increasing demand of energy has led to the modernization of power systems. With advantages like high efficiency, reliability and sustainability of supply and distribution also lies their disadvantages. Modernization of power systems have made the control and transmission unit more computer dependent. Use of open communication channels in NCS have resulted in time delays. The presence of time delays in power systems can also be attributed to intruders, cyber-attacks, communication latencies, computational delays, 
delays due to sensor measurements and even sometimes naturally ( $\mathrm{Li}$ et al., 2018; Sargolzaei et al., 2016). Systems with time delays exhibit oscillations, poor performance and often are difficult to stabilize and control. Thus, the presence of time delays and their effects are inevitable and cannot be ignored during the modelling of physical systems. In power systems, time delays can be present in sensing loop or control loop or both. To the best knowledge of authors, LFC with time delays in both state and control input is still open for research. Therefore, in this article, a novel LFC problem is formulated with time delays present in both state and control input.

There exists a considerable amount of work reported on the control of time delay systems. Stability analysis of linear time varying delay system based on linear matrix inequalities (LMI) using Bessel-Legendre inequalities is reported in Seuret and Gouaisbaiut (2018). Fridman E. (2014) reported a tutorial on Lyapunov based methods for time delay systems. Lechappe et al. (2015) proposed a new predictive scheme for the control of linear time invariant (LTI) system with constant and known delays in the input and unknown disturbances. Predictive control with an application to a DC motor in the presence of external disturbance, unknown uncertainties and an unknown input delay is proposed in Lechappe et al. (2016). Design of sliding mode predictor observer for state estimation and fault reconstruction for output time delay systems using a novel time shift approach is presented in Pinto et al. (2018a). Loukianov et al. (2017) reported a predictor based robust control for uncertain linear delay systems via sliding mode control (SMC) with delays in both state and control loop. A predictor-based observer using a partial differential equation backstepping method for linear systems with output time varying delay is reported in Pinto et al. (2018b). In the field of LFC, the presence of state and input delays are very challenging and has attracted the attention of research community over the last few decades. Most of the articles reported on LFC have either ignored the presence of time delays or have considered a controller that is robust against time delays. Ignorance of time delays in the field of LFC can have a catastrophic effect on the controller design.

Delay dependent stability for LFC with constant and time varying delays based on calculation of delay margin using Lyapunov theorem and LMI is reported in Jiang et al. (2012). Delay dependent robust LFC for time delay power systems using proportional integral derivative controller is reported in Zhang et al. (2013). H-infinity based nonlinear SMC in interconnected power system with constant and time varying delays using delay dependent stability criteria is reported in Prasad et al. (2016). Wen et al. (2015) reported 
event triggered LFC for power systems with communication delays via an event triggered control method. LFC for two area thermal power systems based on estimated time delays and packet loss probability using the markovian approach is proposed in Singh et al. (2016). A novel sliding mode estimation-based controller to predict time delays and state estimation and to reject the disturbance of estimation error is reported in Yan et al. (2017). Sliding mode LFC for multi area time delay power systems with wind power integration is proposed in Mi et al. (2017). Robust H-infinity sliding mode LFC of multi area power systems with time delays taking into account stochastic disturbances induced by integration of renewable energies is proposed in Sun et al. (2018).

The main objective of the LFC scheme is to maintain the system frequency and the interchange power between control areas at the scheduled level (Pandey et al., 2013; Pappachen and Fathima, 2017). In this article, load frequency problems with time delays in state and control loop under uncertain load conditions is investigated using predictionbased ST-SMC. It is also well known that the design of any state feedback controller requires information of all the system states. However, not all the system states are available or are easily measurable. In such cases, system states are estimated using a process called observation. This is done by observers which act a replacement to physical sensors in practice. It should be noted that differentiating a state to obtain other should be avoided as it leads to low signal to noise ratio. The prediction-based ST-SMC is based on estimated state and disturbance. The higher order sliding mode observer (HOSMO) with inherent advantages of robustness, finite time convergence and insensitivity to disturbances estimate system states from the output and control signal. Compared to modern state of the art, observer-based controller designs are advantageous in practice as they minimise the use of physical sensors, unwanted noise, design cost etc. Another component of the proposed design is the disturbance observer (DO). The DO based controller mitigates wide deviations in the frequency under load disturbances. This is done by estimating the unknown disturbance and designing a sliding surface dependent on the estimated disturbance (Li et al., 2014).

The prediction-based ST-SMC uses the estimated system states and ensures finite time convergence of frequency and tie line power deviation under load disturbance with time delays. Unlike higher order SMC, the supremacy of super twisting control (STC) lies in the fact that it only acts on the first-time derivative of sliding surface to counter chattering without any loss in control accuracy. This eliminates the need of increased information demand and also memory to store the information about the higher order time derivatives 
of sliding surface to attenuate chattering. Furthermore, the robustness of the proposed design is validated under ramp and random step load disturbances, power system nonlinearities, integration of renewable energy resource and also with IEEE 39 bus large power system popularly known as New England 39 bus power system. To summarise, the main contributions of this work are:

- Formulation of a novel LFC problem with time delays in state and control input under uncertain load conditions.

- A prediction based chattering free controller is designed to compensate the effect of time delays and to confirm finite time convergence of frequency and tie line power deviations under load disturbance.

- To guarantee robustness of the proposed design under time varying delays, wide range of uncertainties, typical nonlinearities of power systems, with an integration of renewable energy resource and with IEEE 39 bus large power system.

The remainder of the article is outlined as follow: Section 2 deals with the dynamic model of multi area power systems with time delays in state and control loop. Section 3 investigates the design of state and disturbance observers. In section 4, prediction-based ST-SMC is designed based on estimated state and disturbance. In section 5, simulation results are discussed. Finally, the article ends with conclusion and scope for future work in section 6 .

\section{Dynamic model of multi area power systems with time delays}

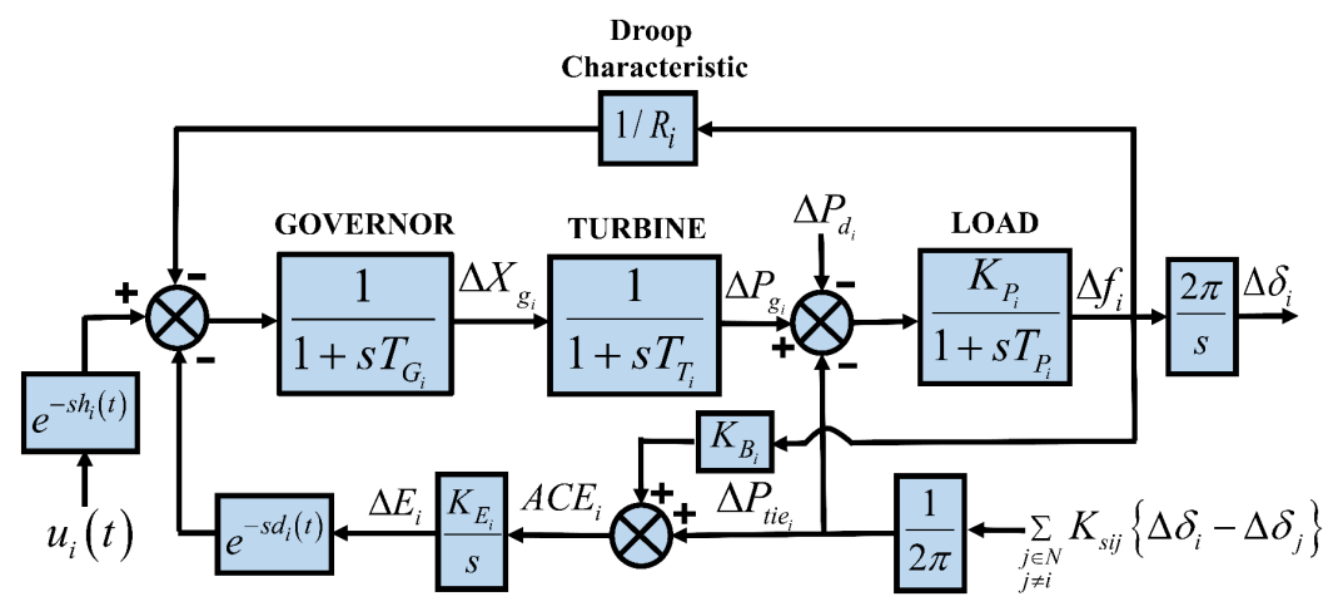

Figure 1. Load frequency control model of power systems with time delays

The foremost step in the design and analysis of a control system is the mathematical modelling of the system. In LFC, linearized model of multi area power system is permissible as only small changes in load are expected during its normal operation 
(Sarkar et al., 2018; Prasad et al., 2017; Mi et al., 2013). Each control area is an assembly of its own governor, turbine, generator and load. The Load frequency model of multi area power systems with time delays in system state and control input is depicted in fig. 1.

The dynamic model for the $i^{\text {th }}$ area is given as,

$$
\begin{aligned}
& \dot{x}_{i}(t)=A_{i} x_{i}(t)+A_{d_{i}} x_{i}\left(\varphi_{i}(t)\right)+B_{i} u_{i}\left(\phi_{i}(t)\right)+\sum_{\substack{j \in N \\
j \neq i}} E_{i j} x_{j}(t)+w_{i}(t) \\
& y_{i}(t)=C_{i} x_{i}(t)
\end{aligned}
$$

where $x_{i}(t) \in \mathfrak{R}^{n_{i}}$ represents state vector, $x_{j}(t) \in \mathfrak{R}^{n_{j}}$ is the neighbouring state vector of $x_{i}(t)$ and $u_{i}(t) \in \mathfrak{R}^{m_{i}}$ is the control vector. Matrices $A_{i} \in \mathfrak{R}^{n_{i} \times n_{i}}, A_{d_{i}} \in \mathfrak{R}^{n_{i} \times n_{i}}, B_{i} \in \mathfrak{R}^{n_{i} \times m_{i}}$ and $E_{i j} \in \mathfrak{R}^{n_{i} \times n_{j}}$ depict system matrix, delay matrix, input matrix and interconnection gain matrix.

In equation (1), $w_{i}(t)=F_{i} \Delta P_{d_{i}}(t), \quad \varphi_{i}(t)=t-d_{i}(t) \leq t \forall t \quad$ and $\quad \phi_{i}(t)=t-h_{i}(t) \leq t \forall t$ where $F_{i} \in \mathfrak{R}^{n_{i} \times k_{i}}$ and $\Delta P_{d_{i}}(t) \in \mathfrak{R}^{k_{i}}$ (p.u. MW) depict disturbance matrix and vector of load disturbance respectively. Variables $d_{i}(t)$ and $h_{i}(t)$ are the delays in system state and control input respectively.

The state variable vector is defined as,

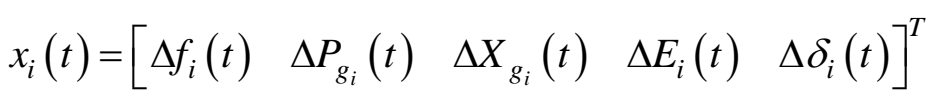

where $\Delta f_{i}(t)$ is the change in frequency $(\mathrm{Hz}) ; \Delta P_{g_{i}}(t)$ is the change in power output (p.u. $\mathrm{MW}) ; \Delta X_{g_{i}}(t)$ is the change in governor valve position (p.u. MW); $\Delta E_{i}(t)$ is the change in integral control (p.u. MW); $\Delta \delta_{i}(t)$ is the change in rotor angle deviation (radian). In equation (1), the matrices $A_{i}, A_{d_{i}}, B_{i}, C_{i}, E_{i j}$ and $F_{i}$ are represented as follow,

$$
A_{i}=\left[\begin{array}{ccccc}
-\frac{1}{T_{P_{i}}} & \frac{K_{P_{i}}}{T_{P_{i}}} & 0 & 0 & \frac{-K_{P_{i}}}{2 \pi T_{P_{i}}} \sum_{\substack{j \in N \\
j \neq i}} K_{s i j} \\
0 & -\frac{1}{T_{T_{i}}} & \frac{1}{T_{T_{i}}} & 0 & 0 \\
-\frac{1}{R_{i} T_{G_{i}}} & 0 & -\frac{1}{T_{G_{i}}} & 0 & 0 \\
K_{E_{i}} K_{B_{i}} & 0 & 0 & 0 & \frac{K_{E_{i}}}{2 \pi} \sum_{\substack{j \in N \\
j \neq i}} K_{s i j} \\
2 \pi & 0 & 0 & 0 & 0
\end{array}\right] B_{i}=\left[\begin{array}{c}
0 \\
0 \\
\frac{1}{T_{G_{i}}} \\
0 \\
0
\end{array}\right] C_{i}=\left[\begin{array}{lllll}
1 & 0 & 0 & 0 & 0
\end{array}\right]
$$


$A_{d_{i}}=\left[\begin{array}{ccccc}0 & 0 & 0 & 0 & 0 \\ 0 & 0 & 0 & 0 & 0 \\ 0 & 0 & 0 & -\frac{1}{T_{G_{i}}} & 0 \\ 0 & 0 & 0 & 0 & 0 \\ 0 & 0 & 0 & 0 & 0\end{array}\right] ; E_{i j}=\left[\begin{array}{ccccc}0 & 0 & 0 & 0 & \frac{K_{P_{i}}}{2 \pi T_{P_{i}}} K_{s i j} \\ 0 & 0 & 0 & 0 & 0 \\ 0 & 0 & 0 & 0 & 0 \\ 0 & 0 & 0 & 0 & -\frac{K_{E_{i}}}{2 \pi} K_{s i j} \\ 0 & 0 & 0 & 0 & 0\end{array}\right] ; F_{i}=\left[\begin{array}{c}-\frac{K_{P_{i}}}{T_{P_{i}}} \\ 0 \\ 0 \\ 0 \\ 0\end{array}\right]$

$K_{s i j}$ (p.u. MW) is the interconnection gain between area $i$ and $j(i \neq j)$ and if there is no exchange of power between $i$ and $j, K_{s i j}=0$.

For the above defined time delay system, following assumptions are made:

Assumption 1: The incremental change of load disturbance $\Delta P_{d_{i}}(t)$ in system (1) is slow changing and bounded such that $\left|w_{i}(t)\right|<\Delta_{o}$, where $\Delta_{o}$ is a positive constant, and its time derivative is also bounded and satisfies $\lim _{t \rightarrow \infty}\left|\dot{w}_{i}(t)\right|=0$ (Liao et al., 2017).

Assumption 2: The function $\phi_{i}(t)$ is differentiable and bounded, i.e. there exist $\delta_{\phi_{i}}>0$, such that,

$0<\left|\dot{\phi}_{i}(t)\right| \leq \delta_{\phi_{i}}, \forall t>0$.

Assumption 3: The time varying delays $d_{i}(t)$ and $h_{i}(t)$ are bounded, so there exist $d_{i_{\max }}>0$ and $h_{i_{\max }}>0$ such that,

$0 \leq d_{i}(t) \leq d_{i_{\max }}$

$0 \leq h_{i}(t) \leq h_{i_{\max }}$

Remark 1: Assumption 2 also implies that $\phi_{i}(t)$ is strictly increasing then the function $\phi_{i}(t)$ is invertible and its inverse $\phi_{i}^{-1}(t)$ is computable (Barragan et al., 2018).

The proposed control scheme for the time delay system (1) consist of dividing $u_{i}(t)$ into two components with each term having a specific purpose (Loukianov et al., 2017).

$u_{i}(t)=u_{o_{i}}(t)+u_{d_{i}}(t)$

The component $u_{d_{i}}(t)$ is used to cancel the time delay in state $A_{d_{i}} x_{i}\left(\varphi_{i}(t)\right)$ in order to enable the design of a predictor. Using $u_{d_{i}}(t)$ results a system which is free from state 
time delay. The component $u_{o_{i}}(t)$ is the prediction based STC that compensates the time delay in the control loop.

Substituting equation (8) in (1) results,

$$
\dot{x}_{i}(t)=A_{i} x_{i}(t)+A_{d_{i}} x_{i}\left(\varphi_{i}(t)\right)+B_{i}\left(u_{o_{i}}\left(\phi_{i}(t)\right)+u_{d_{i}}\left(\phi_{i}(t)\right)\right)+\sum_{\substack{j \in N \\ j \neq i}} E_{i j} x_{j}(t)+w_{i}(t)
$$

Selecting a matrix $\bar{A}_{d_{i}} \in \mathfrak{R}^{m_{i} \times n_{i}}$ such that $A_{d_{i}}=B_{i} \bar{A}_{d_{i}}$ and substituting it in equation (9),

$$
\dot{x}_{i}(t)=A_{i} x_{i}(t)+B_{i}\left(u_{o_{i}}\left(\phi_{i}(t)\right)+u_{d_{i}}\left(\phi_{i}(t)\right)+\bar{A}_{d_{i}} x_{i}\left(\varphi_{i}(t)\right)\right)+\sum_{\substack{j \in N \\ j \neq i}} E_{i j} x_{j}(t)+w_{i}(t)
$$

Now, selecting $u_{d_{i}}(t)=-\bar{A}_{d_{i}} x_{i}\left(\psi_{i}(t)\right)$, where $\psi_{i}(t)=\varphi_{i}\left(\phi_{i}^{-1}(t)\right)$ and substituting it in equation (10) yields (Barragan et al., 2018),

$$
\dot{x}_{i}(t)=A_{i} x_{i}(t)+B_{i} u_{o_{i}}\left(\phi_{i}(t)\right)+\sum_{\substack{j \in N \\ j \neq i}} E_{i j} x_{j}(t)+w_{i}(t)
$$

\section{Design of state and disturbance observer}

As discussed earlier, design of any multivariable state feedback control requires information of all the system states. However, not all the system states are available or are easily measurable. In such cases, estimation of unmeasurable state variables is done by observer and this process is commonly known as observation. State observers serve as a replacement for physical sensors for obtaining unavailable quantities (Liu et al., 2018). In practice, observer-based control design is advantageous as it minimizes the number of sensors required, unwanted noise with the sensors and also design cost. However, observation of system states in the presence of unknown input is very challenging problem in modern control theory. The design of such observers is based on a condition that only output is available without its derivatives (Fridman et al., 2007). In this article, state estimation is done using HOSMO. The HOSMO provide global observation of the states and the output under sufficient and necessary condition of strong observability or strong detectability (Fridman et al., 2008; Fridman et al., 2006). The sliding mode observer (SMO) based on step by step state vector reconstruction require filters at each step due to imperfections of analog devices. However, the use of HOSMOs eliminates the use of filters at each step (Fridman et al., 2008).

The following assumption is necessary for the design of state observer which is discussed in the sequel. 
Assumption 4: The pair $\left(C_{i}, A_{i}\right)$ is observable.

The estimated states are used for the design of prediction-based ST-SMC. Transforming equation (11) using $z_{i} \mapsto T_{i} x_{i}$, where $T_{i}=\left[\begin{array}{lllll}C_{i} & C_{i} A_{i} & \cdot & \cdot & C_{i} A_{i}^{n-1}\end{array}\right]^{T}$.

$\dot{z}_{i}(t)=\Lambda_{i} z_{i}(t)+\Phi_{i} u_{o_{i}}\left(\phi_{i}(t)\right)+\sum_{\substack{j \in N \\ j \neq i}} \Pi_{i j} z_{j}(t)+\Theta_{i}(t)$

$y_{i}(t)=\varpi_{i} z_{i}(t)$

where $\Lambda_{i}=T_{i} A_{i} T_{i}^{-1}, \Phi_{i}=T_{i} B_{i}, \quad \Pi_{i j}=T_{i} E_{i j} T_{j}^{-1}, \Theta_{i}(t)=T_{i} w_{i}(t)$ and $\varpi_{i}=C_{i} T_{i}^{-1}$. The HOSMO takes the form of a fundamental Luenberger observer plus higher order sliding mode differentiator (Fridman et al., 2007; Mohamed et al., 2016)

$$
\dot{\hat{z}}_{i}(t)=\Lambda_{i} \hat{z}_{i}(t)+\Phi_{i} u_{o_{i}}\left(\phi_{i}(t)\right)+\sum_{\substack{j \in N \\ j \neq i}} \Pi_{i j} \hat{z}_{j}(t)+L_{i} C_{i} e_{i}(t)+\lambda_{i}\left(e_{i}(t)\right)+\hat{w}_{i}(t)
$$

where $\hat{z}_{i}(t)$ is the estimation of $z_{i}(t), L_{i}$ is the designed gain matrix, $e_{i}(t)=x_{i}(t)-\hat{x}_{i}(t)$ and $\hat{w}_{i}(t)$ is the estimated disturbance whose dynamics will be given in the sequel. Using $e_{i}(t)$, one selects the correction term $\lambda_{i}\left(e_{i}(t)\right)$ as follows (Chalanga et al., 2016),

$$
\lambda_{i}\left(e_{i}(t)\right)=\left[\begin{array}{cr}
\alpha_{1_{i}}\left|e_{i}(t)\right|^{4 / 5} & \operatorname{sign}\left(e_{i}(t)\right) \\
\alpha_{2_{i}}\left|e_{i}(t)\right|^{3 / 4} & \operatorname{sign}\left(e_{i}(t)\right) \\
\alpha_{3_{i}}\left|e_{i}(t)\right|^{2 / 3} & \operatorname{sign}\left(e_{i}(t)\right) \\
\alpha_{4_{i}}\left|e_{i}(t)\right|^{1 / 2} & \operatorname{sign}\left(e_{i}(t)\right) \\
\alpha_{5_{i}} \operatorname{sign}\left(e_{i}(t)\right)
\end{array}\right]
$$

It should be noted that choice of constant gains $\alpha_{1_{i}}, \ldots \ldots ., \alpha_{5_{i}}$ are not unique, however in in this work they have been selected as positive constants. System states can be recovered back using same transformation now in the form $\hat{x}_{i}=T_{i}^{-1} \hat{z}_{i}$ as,

$$
\dot{\hat{x}}_{i}(t)=A_{i} \hat{x}_{i}(t)+B_{i} u_{o_{i}}\left(\phi_{i}(t)\right)+\sum_{\substack{j \in N \\ j \neq i}} E_{i j} \hat{x}_{j}(t)+L_{i} C_{i} e_{i}(t)+\lambda_{i}\left(e_{i}(t)\right)+\hat{w}_{i}(t)
$$

Considering $w_{i}(t)$ as a state vector, the augmented model of system (11) can be rewritten in the following form (Wang et al., 2016),

$$
\left[\begin{array}{c}
\dot{x}_{i}(t) \\
\dot{w}_{i}(t)
\end{array}\right]=\left[\begin{array}{cc}
A_{i} & I \\
0 & 0
\end{array}\right]\left[\begin{array}{c}
x_{i}(t) \\
w_{i}(t)
\end{array}\right]+\left[\begin{array}{c}
B_{i} \\
0
\end{array}\right] u_{i}\left(\phi_{i}(t)\right)+\left[\begin{array}{cc}
\sum_{j \in N} E_{i j} & 0 \\
j \neq i & \\
0 & 0
\end{array}\right]\left[\begin{array}{c}
x_{j}(t) \\
w_{i}(t)
\end{array}\right]+\left[\begin{array}{c}
0 \\
\dot{w}_{i}(t)
\end{array}\right]
$$


The HOSMO along with disturbance observer in the matrix form can be written as,

$$
\begin{aligned}
{\left[\begin{array}{c}
\dot{\hat{x}}_{i}(t) \\
\dot{\hat{w}}_{i}(t)
\end{array}\right] } & =\left[\begin{array}{cc}
A_{i} & I \\
0 & 0
\end{array}\right]\left[\begin{array}{c}
\hat{x}_{i}(t) \\
\hat{w}_{i}(t)
\end{array}\right]+\left[\begin{array}{c}
B_{i} \\
0
\end{array}\right] u_{i}\left(\phi_{i}(t)\right)+\left[\begin{array}{cc}
\sum_{j \in N} E_{i j} & 0 \\
j \neq i & \\
0 & 0
\end{array}\right]\left[\begin{array}{c}
\hat{x}_{j}(t) \\
0
\end{array}\right] \\
& +\left[\begin{array}{c}
L_{i} C_{i} \\
\beta_{i}
\end{array}\right] e_{i}(t)+\left[\begin{array}{c}
\lambda_{i}\left(e_{i}(t)\right) \\
0
\end{array}\right]
\end{aligned}
$$

Reminding that $e_{i}(t)=x_{i}(t)-\hat{x}_{i}(t)$ and defining $\tilde{w}_{i}(t)=w_{i}(t)-\hat{w}_{i}(t)$, the observer error system is obtained as,

$\left[\begin{array}{c}\dot{e}_{i}(t) \\ \dot{\tilde{w}}_{i}(t)\end{array}\right]=\left[\begin{array}{cc}A_{i}-L_{i} C_{i} & I \\ -\beta_{i} & 0\end{array}\right]\left[\begin{array}{c}e_{i}(t) \\ \tilde{w}_{i}(t)\end{array}\right]+\left[\begin{array}{c}0 \\ \dot{w}_{i}(t)\end{array}\right]-\left[\begin{array}{c}\lambda_{i}\left(e_{i}(t)\right) \\ 0\end{array}\right]$

Defining $\bar{A}_{i}=\left[\begin{array}{cc}A_{i}-L_{i} C_{i} & I \\ -\beta_{i} & 0\end{array}\right]$ and based on assumption 4, the observer gain matrices $L_{i}$ and $\beta_{i}$ are selected such that there exist a matrix $H_{i}=\left[\begin{array}{cc}S_{i} & 0 \\ 0 & \theta_{i}\end{array}\right]$ which is the solution of Lyapunov equation (19), with positive definite matrices $S_{i}>0$ and $\theta_{i}>0$.

$\bar{A}_{i}^{T} H_{i}+H_{i} \bar{A}_{i}=-R_{i}$ where $R_{i}>0$.

In the following, using a candidate Lyapunov function, we ensure that the error dynamic equation (18) is asymptotically stable and is independent of the unknown disturbance $w_{i}(t)$.

Theorem 1: The error dynamic equation (18) is asymptotically stable and is independent of the unknown disturbance $w_{i}(t)$ provided the roots of $\bar{A}_{i}$ have negative real parts or lie at the left half of complex plane.

Proof: Combining the state and disturbance estimation error as $\omega_{i}(t)=\left[\begin{array}{c}e_{i}(t) \\ \tilde{w}_{i}(t)\end{array}\right]$, we consider a candidate Lyapunov function as,

$V_{i}(t)=\omega_{i}^{T}(t) H_{i} \omega_{i}(t)$

Taking the derivative of (20) along the trajectories of (18),

$\dot{V}_{i}(t)=\dot{\omega}_{i}^{T}(t) H_{i} \omega_{i}(t)+\omega_{i}^{T}(t) H_{i} \dot{\omega}_{i}(t)$

Substituting $\dot{\omega}_{i}(t)$ from equation (18) in (21), 


$$
\begin{array}{r}
\dot{V}_{i}(t)=\left\{\omega_{i}^{T}(t) \bar{A}_{i}^{T}+\left[\begin{array}{c}
0 \\
\dot{w}_{i}(t)
\end{array}\right]^{T}-\left[\begin{array}{c}
\lambda_{i}\left(e_{i}(t)\right) \\
0
\end{array}\right]\right\} H_{i} \omega_{i}(t) \\
+\omega_{i}^{T}(t) H_{i}\left\{\bar{A}_{i} \omega_{i}(t)+\left[\begin{array}{c}
0 \\
\dot{w}_{i}(t)
\end{array}\right]-\left[\begin{array}{c}
\lambda_{i}\left(e_{i}(t)\right) \\
0
\end{array}\right]\right\}
\end{array}
$$

Based on assumption 1, equation (22) can be rewritten as follow,

$$
\dot{V}_{i}(t)=\omega_{i}^{T}(t)\left\{\bar{A}_{i}^{T} H_{i}+H_{i} \bar{A}_{i}\right\} \omega_{i}(t)-\left[\begin{array}{c}
\lambda_{i}\left(e_{i}(t)\right) \\
0
\end{array}\right]^{T} H_{i} \omega_{i}(t)-\omega_{i}^{T}(t) H_{i}\left[\begin{array}{c}
\lambda_{i}\left(e_{i}(t)\right) \\
0
\end{array}\right]
$$

Using (19), equation (23) can be rewritten as,

$$
\dot{V}_{i}(t)=-\omega_{i}^{T}(t) R_{i} \omega_{i}(t)-2 \omega_{i}^{T}(t) H_{i}\left[\begin{array}{c}
\lambda_{i}\left(e_{i}(t)\right) \\
0
\end{array}\right]
$$

Reminding $\omega_{i}(t)=\left[\begin{array}{c}e_{i}(t) \\ \tilde{w}_{i}(t)\end{array}\right]$ and $H_{i}=\left[\begin{array}{cc}S_{i} & 0 \\ 0 & \theta_{i}\end{array}\right]$, equation (24) can be reduced to the following form,

$$
\dot{V}_{i}(t)=-\omega_{i}^{T}(t) R_{i} \omega_{i}(t)-2 e_{i}(t) S_{i} \lambda_{i}\left(e_{i}(t)\right)
$$

By the proper selection of constant gains of the correction term $\lambda_{i}\left(e_{i}(t)\right)$ which in this case are positive constants, we can confirm that, $\dot{V}_{i}(t)<0$. This shows that the observation error is asymptotically stable. This completes the proof.

\section{Prediction based super twisting controller using disturbance observer}

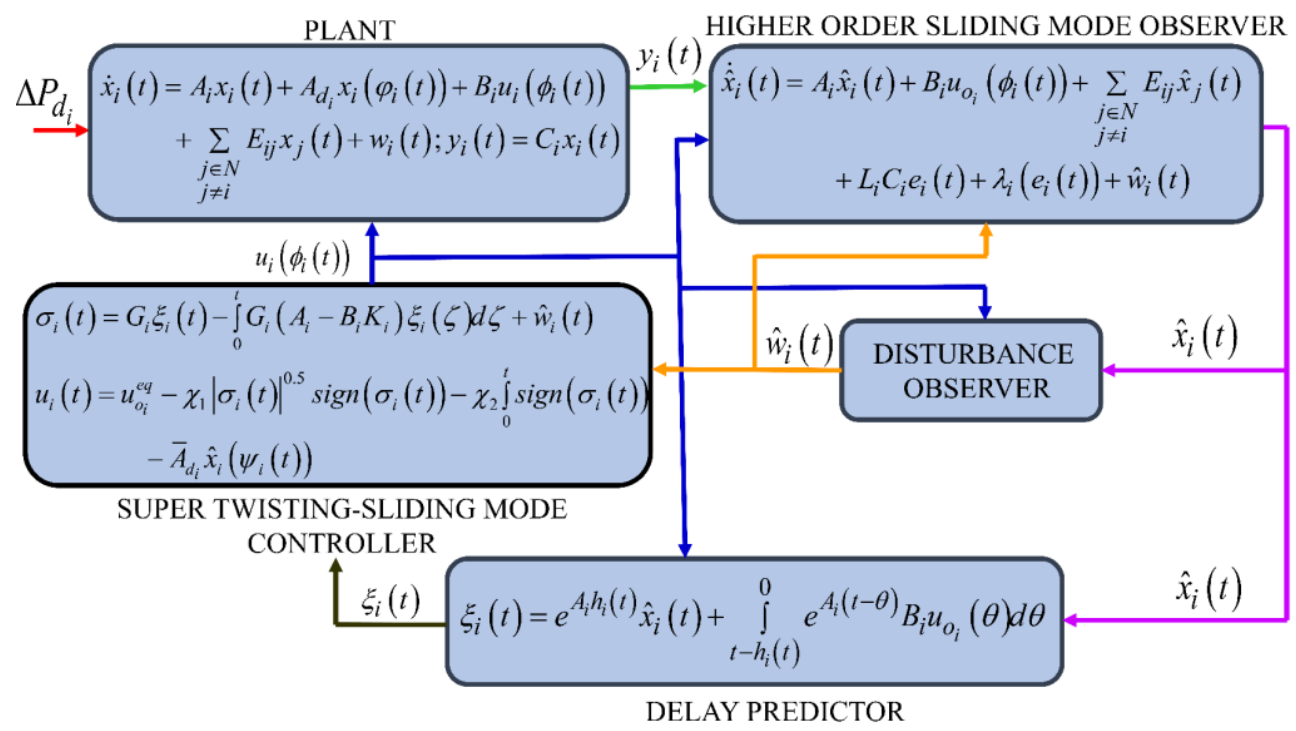

Figure 2. Block diagram of prediction-based ST-SMC using DO 
The proposed prediction based STC using estimated states and disturbance is shown in fig. 2. The said control scheme results in equation (15) which is perfectly free from state time delays. In order to compensate the time delay in the control input i.e. $u_{o_{i}}\left(\phi_{i}(t)\right)$ which can also be written as $u_{o_{i}}\left(t-h_{i}(t)\right)$, a delay predictor is designed of the form (Loukianov et al., 2017; Lechappe et al., 2018, 2015),

$$
\xi_{i}(t)=e^{A_{i} h_{i}(t)} \hat{x}_{i}(t)+\int_{t-h_{i}(t)}^{t} e^{A_{i}(t-\theta)} B_{i} u_{o_{i}}(\theta) d \theta
$$

where $\xi_{i}(t) \in \mathfrak{R}^{n_{i}}$ depicts the predictor state compensating input delay. The computation of $\xi_{i}(t)$ is generally difficult to perform because of an integral term. The integral in (26) can be approximated in real time by various numerical quadrature rules like rectangular, trapezoidal, Simpson's $1 / 3^{\text {rd }}$ rules etc. In this case, the integral is discretised in finite number of points using backward rectangular rule which can be referred from Zhong, 2006.

The derivative of (26) is obtained as,

$$
\begin{aligned}
\dot{\xi}_{i}(t)= & e^{A_{i} h_{i}(t)} \dot{\hat{x}}_{i}(t)+A_{i} \dot{h}_{i}(t) e^{A_{i} h_{i}(t)} \hat{x}_{i}(t)+B_{i} u_{o_{i}}(t)-\left(1-\dot{h}_{i}(t)\right) e^{A_{i} h_{i}(t)} B_{i} u_{o_{i}}\left(t-h_{i}(t)\right) \\
& +A_{i} \int_{t-h_{i}(t)}^{t} e^{A_{i}(t-\theta)} B_{i} u_{o_{i}}(\theta) d \theta
\end{aligned}
$$

Substituting $\dot{\hat{x}}_{i}(t)$ from equation (15) in equation (27) and solving further,

$$
\begin{gathered}
\dot{\xi}_{i}(t)=A_{i} e^{A_{i} h_{i}(t)} \hat{x}_{i}(t)+e^{A_{i} h_{i}(t)} B_{i} u_{o_{i}}\left(t-h_{i}(t)\right)+e^{A_{i} h_{i}(t)} \sum_{\substack{j \in N \\
j \neq i}} E_{i j} \hat{x}_{j}(t)+e^{A_{i} h_{i}(t)} L_{i} C_{i} e_{i}(t) \\
+e^{A_{i} h_{i}(t)} \lambda_{i}\left(e_{i}(t)\right)+e^{A_{i} h_{i}(t)} \hat{w}_{i}(t)+A_{i} \dot{h}_{i}(t) e^{A_{i} h_{i}(t)} \hat{x}_{i}(t)+B_{i} u_{o_{i}}(t) \\
\quad-\left(1-\dot{h}_{i}(t)\right) e^{A_{i} h_{i}(t)} B_{i} u_{o_{i}}\left(t-h_{i}(t)\right)+A_{i} \int_{t-h_{i}(t)}^{t} e^{A_{i}(t-\theta)} B_{i} u_{o_{i}}(\theta) d \theta
\end{gathered}
$$

Substituting $A_{i} \xi_{i}(t)=A_{i} e^{A_{i} h_{i}(t)} \hat{x}_{i}(t)+A_{i} \int_{t-h_{i}(t)}^{t} e^{A_{i}(t-\theta)} B_{i} u_{o_{i}}(\theta) d \theta$ in the above equation $(28)$,

$$
\begin{gathered}
\dot{\xi}_{i}(t)=A_{i} \xi_{i}(t)+B_{i} u_{o_{i}}(t)+e^{A_{i} h_{i}(t)} \sum_{\substack{j \in N \\
j \neq i}} E_{i j} \hat{x}_{j}(t)+e^{A_{i} h_{i}(t)} L_{i} C_{i} e_{i}(t)+e^{A_{i} h_{i}(t)} \lambda_{i}\left(e_{i}(t)\right) \\
+e^{A_{i} h_{i}(t)} \hat{w}_{i}(t)+A_{i} \dot{h}_{i}(t) e^{A_{i} h_{i}(t)} \hat{x}_{i}(t)+\dot{h}_{i}(t) e^{A_{i} h_{i}(t)} B_{i} u_{o_{i}}\left(t-h_{i}(t)\right)
\end{gathered}
$$

Design of SMC involves two fundamental steps: first is the design of sliding surface and second is the design of control law that drives the system states from any initial condition to the sliding surface in finite time and forces the system states to remain on it thereafter. 
In this work, a PI type sliding surface based on predictor state $\xi_{i}(t)$ and an estimated disturbance $\hat{w}_{i}(t)$ is used to improve the overall dynamic performance under mismatched uncertainties and nonlinearities (Mi et al., 2013). The following assumption is necessary for the design of controller which is discussed in the sequel.

Assumption 5: The pair $\left(A_{i}, B_{i}\right)$ is controllable. It implies there exists a matrix $K_{i}$ such that $\left(A_{i}-B_{i} K_{i}\right)$ is Hurwitz and this ensures existence of a symmetric positive matrix $P_{i}$, which is the solution of Lyapunov equation,

$$
\left(A_{i}-B_{i} K_{i}\right)^{T} P_{i}+P_{i}\left(A_{i}-B_{i} K_{i}\right)=-Q_{i} \text { where } Q_{i}>0 \text {. }
$$

A PI type sliding surface based on predictor state and estimated disturbance is selected as follow,

$$
\sigma_{i}(t)=G_{i} \xi_{i}(t)-\int_{0}^{t} G_{i}\left(A_{i}-B_{i} K_{i}\right) \xi_{i}(\zeta) d \zeta+\hat{w}_{i}(t)
$$

where $\sigma_{i}(t)$ is the $i^{t h}$ area sliding surface, matrix $G_{i}$ is selected such that $G_{i} B_{i}$ is nonsingular. In this work, we select $G_{i}$ for the $i^{\text {th }}$ area as, $G_{i}=\left[\begin{array}{lllll}0 & 0 & 1 / T_{G_{i}} & 0 & 0\end{array}\right]$.

Based on assumption 1, differentiating equation (31) and solving further,

$$
\dot{\sigma}_{i}(t)=G_{i} \dot{\xi}_{i}(t)-G_{i}\left(A_{i}-B_{i} K_{i}\right) \xi_{i}(t)
$$

Substituting equation (29) in (32),

$$
\begin{gathered}
\dot{\sigma}_{i}(t)=G_{i}\left\{\begin{array}{c}
A_{i} \xi_{i}(t)+B_{i} u_{o_{i}}(t)+e^{A_{i} h_{i}(t)} \sum_{\substack{j \in N \\
j \neq i}} E_{i j} \hat{x}_{j}(t)+e^{A_{i} h_{i}(t)} L_{i} C_{i} e_{i}(t)+e^{A_{i} h_{i}(t)} \hat{w}_{i}(t) \\
+e^{A_{i} h_{i}(t)} \lambda_{i}\left(e_{i}(t)\right)+A_{i} \dot{h}_{i}(t) e^{A_{i} h_{i}(t)} \hat{x}_{i}(t)+\dot{h}_{i}(t) e^{A_{i} h_{i}(t)} B_{i} u_{o_{i}}\left(t-h_{i}(t)\right)
\end{array}\right\} \\
-G_{i}\left(A_{i}-B_{i} K_{i}\right) \xi_{i}(t) \\
\dot{\sigma}_{i}(t)=G_{i} B_{i} K_{i} \xi_{i}(t)+G_{i} B_{i} u_{o_{i}}(t)+G_{i} e^{A_{i} h_{i}(t)} \sum_{\substack{j \in N \\
j \neq i}} E_{i j} \hat{x}_{j}(t)+G_{i} e^{A_{i} h_{i}(t)} L_{i} C_{i} e_{i}(t) \\
+G_{i} e^{A_{i} h_{i}(t)} \hat{w}_{i}(t)+G_{i} e^{A_{i} h_{i}(t)} \lambda_{i}\left(e_{i}(t)\right)+G_{i} A_{i} \dot{h}_{i}(t) e^{A_{i} h_{i}(t)} \hat{x}_{i}(t) \\
+G_{i} \dot{h}_{i}(t) e^{A_{i} h_{i}(t)} B_{i} u_{o_{i}}\left(t-h_{i}(t)\right)
\end{gathered}
$$

The equivalent control law on the sliding mode is obtained by substituting $\dot{\sigma}_{i}(t)=0$ in the above equation (34), 
$u_{o_{i}}^{e q}(t)=\frac{-1}{G_{i} B_{i}}\left[\begin{array}{c}G_{i} B_{i} K_{i} \xi_{i}(t)+G_{i} e^{A_{i} h_{i}(t)} \sum_{\substack{j \in N \\ j \neq i}} E_{i j} \hat{x}_{j}(t)+G_{i} e^{A_{i} h_{i}(t)} L_{i} C_{i} e_{i}(t)+G_{i} e^{A_{i} h_{i}(t)} \lambda_{i}\left(e_{i}(t)\right) \\ +G_{i} e^{A_{i} h_{i}(t)} \hat{w}_{i}(t)+G_{i} A_{i} \dot{h}_{i}(t) e^{A_{i} h_{i}(t)} \hat{x}_{i}(t)+G_{i} \dot{h}_{i}(t) e^{A_{i} h_{i}(t)} B_{i} u_{o_{i}}\left(t-h_{i}(t)\right)\end{array}\right]$

The above formulated equivalent control compensates the time delay in the input loop and also ensures finite time convergence of the system states. The prediction based-STC $u_{o_{i}}(t)$ in equation (8) which is main focus of this article to achieve chattering free control and also to overcome the uncertainties in the system consist of three parts namely, the equivalent control law $u_{o_{i}}^{e q}(t)$ designed by substituting $\dot{\sigma}_{i}(t)=0$, the continuous state function and the discontinuous input with an integrator (Chalanga et al., 2016; Heng et al., 2017). Thus, $u_{o_{i}}(t)$ in equation (8) is achieved as,

$$
\begin{aligned}
u_{o_{i}}(t)=\frac{-1}{G_{i} B_{i}}\left[\begin{array}{c}
G_{i} B_{i} K_{i} \xi_{i}(t)+G_{i} e^{A_{i} h_{i}(t)} \sum_{\substack{j \in N \\
j \neq i}} E_{i j} \hat{x}_{j}(t)+G_{i} e^{A_{i} h_{i}(t)} L_{i} C_{i} e_{i}(t)+G_{i} e^{A_{i} h_{i}(t)} \lambda_{i}\left(e_{i}(t)\right) \\
+G_{i} e^{A_{i} h_{i}(t)} \hat{w}_{i}(t)+G_{i} A_{i} \dot{h}_{i}(t) e^{A_{i} h_{i}(t)} \hat{x}_{i}(t)+G_{i} \dot{h}_{i}(t) e^{A_{i} h_{i}(t)} B_{i} u_{o_{i}}\left(t-h_{i}(t)\right)
\end{array}\right] \\
-\chi_{1}\left|\sigma_{i}(t)\right|^{0.5} \operatorname{sign}\left(\sigma_{i}(t)\right)-\chi_{2} \int_{0}^{t} \operatorname{sign}\left(\sigma_{i}(t)\right) d \tau
\end{aligned}
$$

where $\chi_{1}$ and $\chi_{2}$ are the positive constants. Reminding $\left|w_{i}(t)\right|<\Delta_{o}$, we select $\chi_{1}=1.5 \sqrt{\Delta_{o}}$ and $\chi_{2}=1.1 \Delta_{o}$. Now, using (8), the proposed prediction based chattering free control signal compensating both state and input delays and also the uncertainties can now be given as,

$$
\begin{aligned}
u_{i}(t)= & \frac{-1}{G_{i} B_{i}}\left[\begin{array}{c}
G_{i} B_{i} K_{i} \xi_{i}(t)+G_{i} e^{A_{i} h_{i}(t)} \sum_{\substack{j \in N \\
j \neq i}} E_{i j} \hat{x}_{j}(t)+G_{i} e^{A_{i} h_{i}(t)} L_{i} C_{i} e_{i}(t)+G_{i} e^{A_{i} h_{i}(t)} \lambda_{i}\left(e_{i}(t)\right) \\
+G_{i} e^{A_{i} h_{i}(t)} \hat{w}_{i}(t)+G_{i} A_{i} \dot{h}_{i}(t) e^{A_{i} h_{i}(t)} \hat{x}_{i}(t)+G_{i} \dot{h}_{i}(t) e^{A_{i} h_{i}(t)} B_{i} u_{o_{i}}\left(t-h_{i}(t)\right)
\end{array}\right] \\
& -\chi_{1}\left|\sigma_{i}(t)\right|^{0.5} \operatorname{sign}\left(\sigma_{i}(t)\right)-\chi_{2} \int_{0}^{t} \operatorname{sign}\left(\sigma_{i}(t)\right) d \tau-\bar{A}_{d_{i}} \hat{x}_{i}\left(\psi_{i}(t)\right)
\end{aligned}
$$

Rewriting the closed loop equation of system in terms of predictive states by substituting $u_{o_{i}}(t)$ from equation (36) in equation (29). Upon solving, $\dot{\xi}_{i}(t)$ is reduced to the following form,

$$
\dot{\xi}_{i}(t)=\left(A_{i}-B_{i} K_{i}\right) \xi_{i}(t)-B_{i} \chi_{1}\left|\sigma_{i}(t)\right|^{0.5} \operatorname{sign}\left(\sigma_{i}(t)\right)-B_{i} \chi_{2} \int_{0}^{t} \operatorname{sign}\left(\sigma_{i}(t)\right) d \tau
$$


Rewriting the dynamics of (32) after substituting (38) we get,

$\dot{\sigma}_{i}(t)=-G_{i} B_{i} \chi_{1}\left|\sigma_{i}(t)\right|^{0.5} \operatorname{sign}\left(\sigma_{i}(t)\right)-G_{i} B_{i} \chi_{2} \int_{0}^{t} \operatorname{sign}\left(\sigma_{i}(t)\right) d \tau$

It should be noted that the proposed prediction-based control scheme results in a closed loop system (38) which is free from any state and input time delays. Therefore, unlike delay dependent stability conditions for closed loop systems with time delays, in this article the asymptotic stability of the closed loop system can be proved by delay independent Lyapunov functional candidate.

Theorem 2: If Assumptions 2 and 3 hold true, the trajectory $x_{i}(t)$ of the $i^{\text {th }}$ area tends to zero provided $G_{i} B_{i}$ is non-singular and the super twisting controller gains $\chi_{1}>0, \chi_{2}>0$.

Proof: Considering a candidate Lyapunov function as,

$V_{i}(t)=0.5 \sigma_{i}(t)^{2}$

Taking the time derivative of (40),

$\dot{V}_{i}(t)=\sigma_{i}(t) \dot{\sigma}_{i}(t)$

Substituting equation (39) in (41),

$\dot{V}_{i}(t)=\sigma_{i}(t)\left\{-G_{i} B_{i} \chi_{1}\left|\sigma_{i}(t)\right|^{0.5} \operatorname{sign}\left(\sigma_{i}(t)\right)-G_{i} B_{i} \chi_{2} \int_{0}^{t} \operatorname{sign}\left(\sigma_{i}(t)\right) d \tau\right\}$

With proper selection of matrix $G_{i}$ as mentioned in section 4 of the article and also ensuring that $G_{i} B_{i}$ is non-singular which in this article is $G_{i} B_{i}=1$, we can conclude that, $\dot{V}_{i}(t)<0$.

Equation (43) means that the sliding surface $\sigma_{i}(t)$ is asymptotically stable and thus tends to zero. Since the sliding surface $\sigma_{i}(t)$ is a function of predictor state $\xi_{i}(t)$, thus it can be deduced that $\xi_{i}(t)$ also tends to zero. This implies that $\hat{x}_{i}(t)$ tends to zero and since the error dynamic equation is stable (from theorem 1), we can conclude that $x_{i}(t)$ tends to zero.

This completes the proof.

\section{Results and Discussion}

In order to illustrate the effectiveness and feasibility of the proposed control design, three area interconnected power system model is considered with time delays in state and 
control loop. The basic parameters of three area interconnected power systems are given in Table 1 (Mi et al., 2013).

TABLE 1 POWER SYSTEM PARAMETER VALUES

\begin{tabular}{|c|c|c|c|c|c|c|c|c|}
\hline Area & $T_{P_{i}}$ & $K_{P_{i}}$ & $T_{T_{i}}$ & $T_{G_{i}}$ & $R_{i}$ & $K_{E_{i}}$ & $K_{B_{i}}$ & $K_{s i j}$ \\
\hline 1 & 20 & 120 & 0.3 & 0.08 & 2.4 & 10 & 0.41 & 0.55 \\
\hline 2 & 25 & 112.5 & 0.33 & 0.072 & 2.7 & 9 & 0.37 & 0.65 \\
\hline 3 & 20 & 115 & 0.35 & 0.07 & 2.5 & 7.1 & 0.4 & 0.545 \\
\hline
\end{tabular}

\section{A. Performance analysis with constant time delays}

In this case the proposed control scheme is validated with different constant time delays in the system state and control input. The time delays considered in system state in area 1,2 and 3 are 0.05 second, 0.1 second and 0.15 second respectively. The input time delays considered in area 1, 2 and 3 are 0.03 second, 0.08 second and 1 second respectively.

Scenario 1: A three-area interconnected power system model is considered with initial condition $x_{i}(0)=\left[\begin{array}{lllll}0.01 & 0.01 & 0.01 & 0.01 & 0.01\end{array}\right]^{T}$. The frequency deviation is found to be within acceptable limit in each area with chattering free control signal (see figs. 3(a) $\&$ (b)). The HOSMO estimates the system states from the output and control signal (see figs. 4(a), (b), (c) \& (d)). In practice, observer-based controller design is advantageous as system states are not always available for measurement or are difficult to measure. In that case observers act a replacement for the physical sensors.

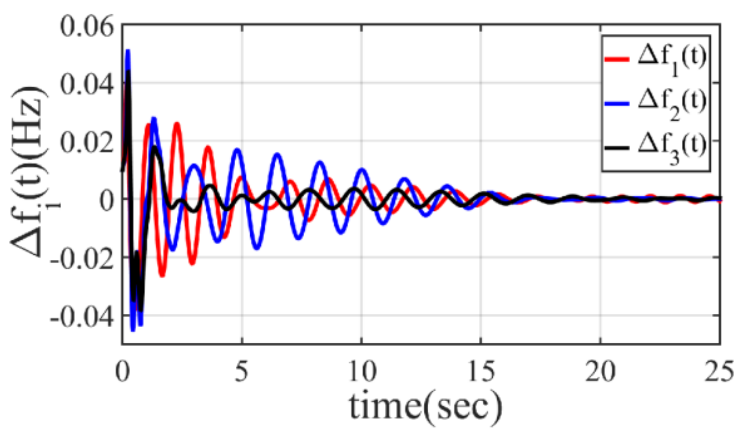

(a) $\Delta f_{i}(t)$

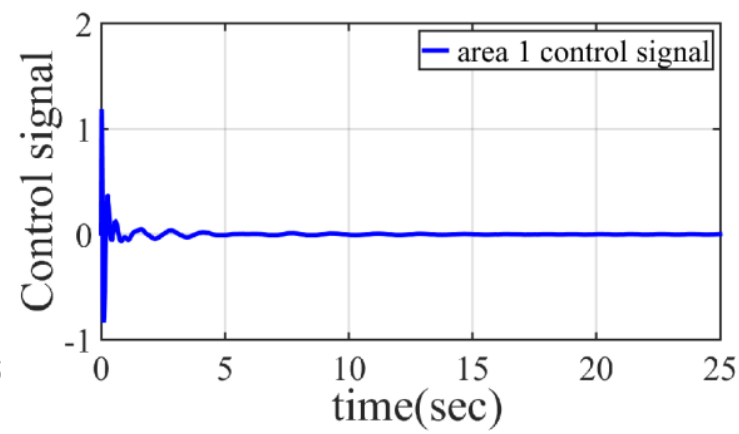

(b) Control signal

Figure 3. Response using proposed design with initial condition 


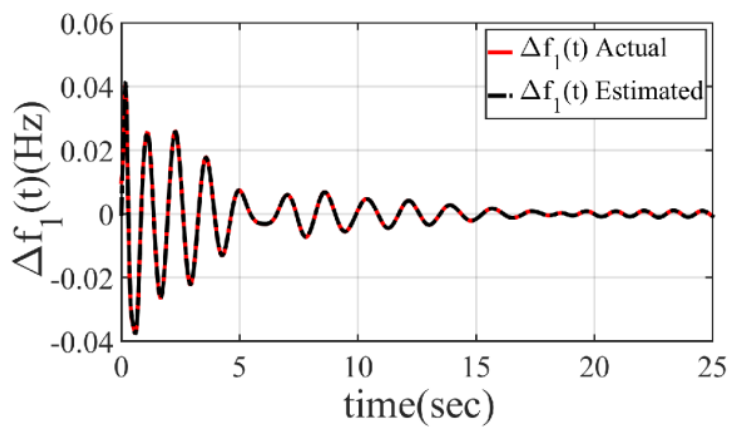

(a) $\Delta \hat{f}_{1}(t)$

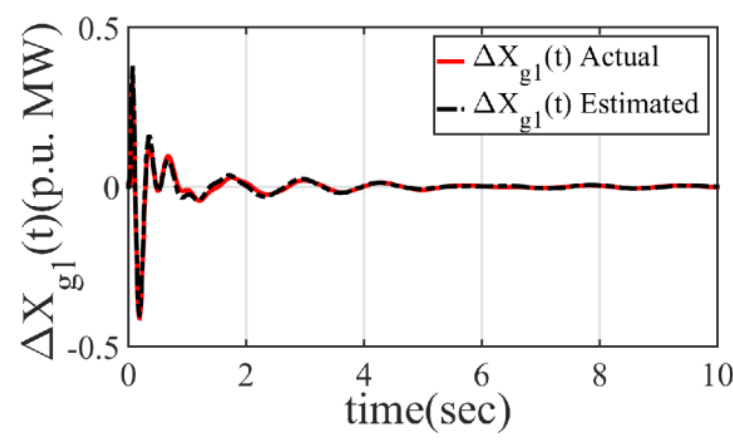

(c) $\Delta \hat{X}_{g_{1}}(t)$

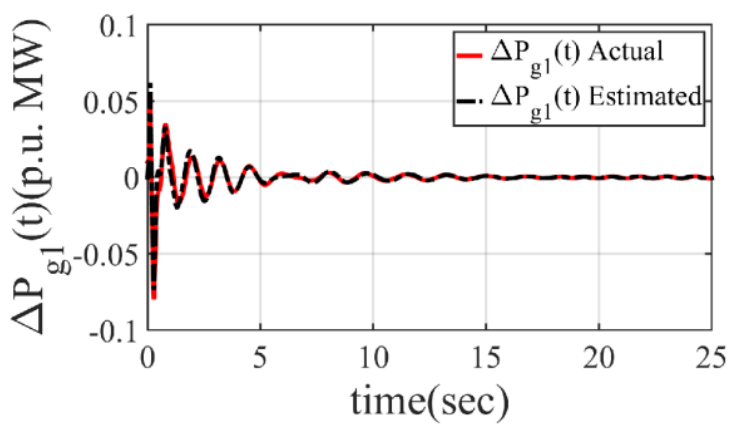

(b) $\Delta \hat{P}_{g_{1}}(t)$

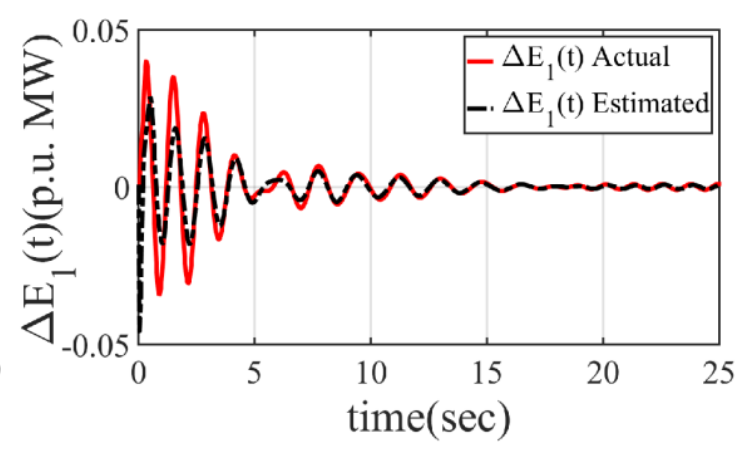

(d) $\Delta \hat{E}_{1}(t)$

Figure 4. Comparison of actual and estimated state

Scenario 2: In this case, step load disturbance of $\Delta P_{d_{1}}(t)=0.02$ p.u. MW, $\Delta P_{d_{2}}(t)=0.015$ p.u. MW and $\Delta P_{d_{3}}(t)=0.01$ p.u. MW is applied in area 1,2 and 3 respectively. The load disturbances are applied at time $t=5 \mathrm{sec}$. The proposed design confirms finite time convergence of frequency and tie line power deviation with chattering free control signal. The presence of time delays in the system produces oscillations in the response, however it perishes out in finite time (see figs. 5(a), (b) and (c)). The disturbance observer estimates the disturbance over wide range and ensures frequency deviations under load disturbance to be within acceptable limit (see fig. 5(d)).

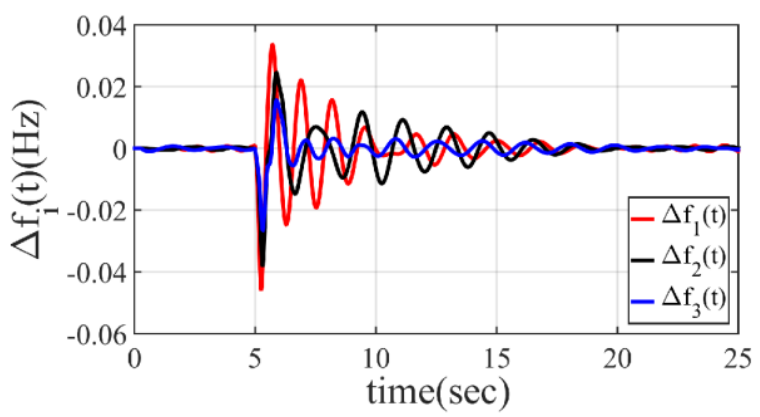

(a) $\Delta f_{i}(t)$

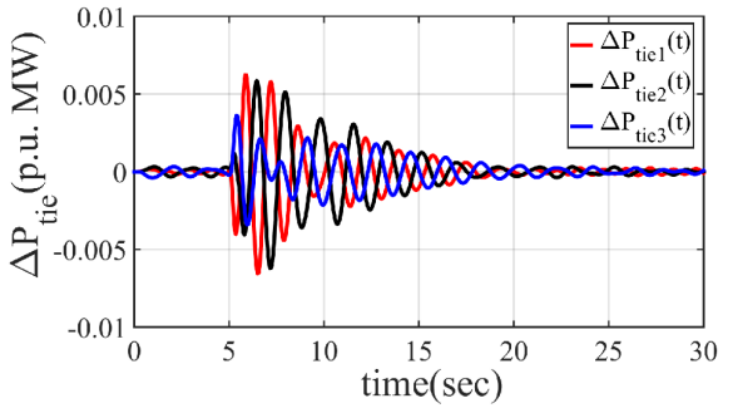

(b) $\Delta P_{t i e_{i}}(t)$ 


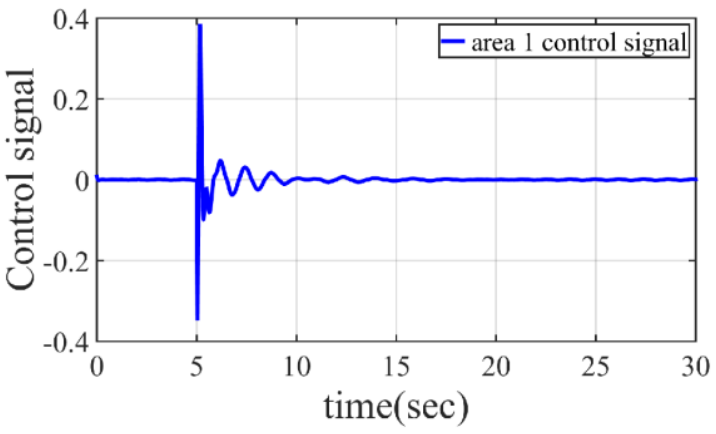

(c) Control signal

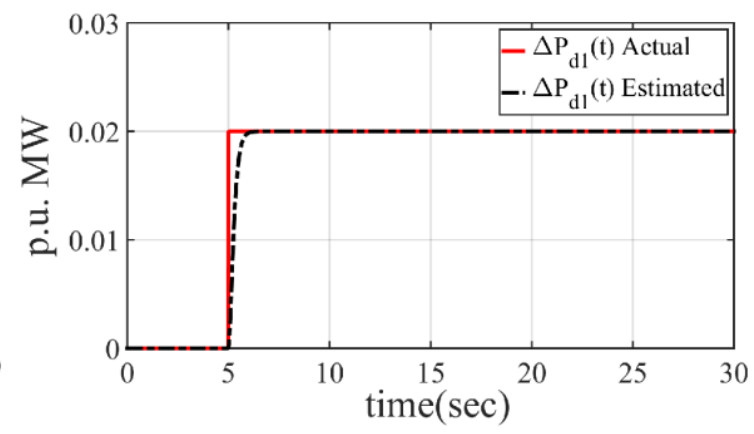

(d) Estimated disturbance

Figure 5. Response using proposed design under step load disturbance

B. Performance analysis with time varying delays

In practical applications, the assumption of constant time delays become too restrictive. In this case, the proposed control design is validated in the presence real time operating conditions. This is achieved by incorporating time varying delays in each area of power systems. These time varying delays have a chance of varying from area to area. However, with same network protocols and measurement technique in different areas and the transmission medium together with the physical transmission distance to be almost same, this would guarantee all delays vary in the same manner in each area (Yang et al. 2018). The time varying delays in state and input considered in each area can be seen from figs. 6(a) \& (b). A step load disturbance of $\Delta P_{d_{1}}(t)=0.02$ p.u. MW, $\Delta P_{d_{2}}(t)=0.015$ p.u. MW and $\Delta P_{d_{3}}(t)=0.01$ p.u. $\mathrm{MW}$ is applied in area 1,2 and 3 respectively at time $t=0$ seconds.

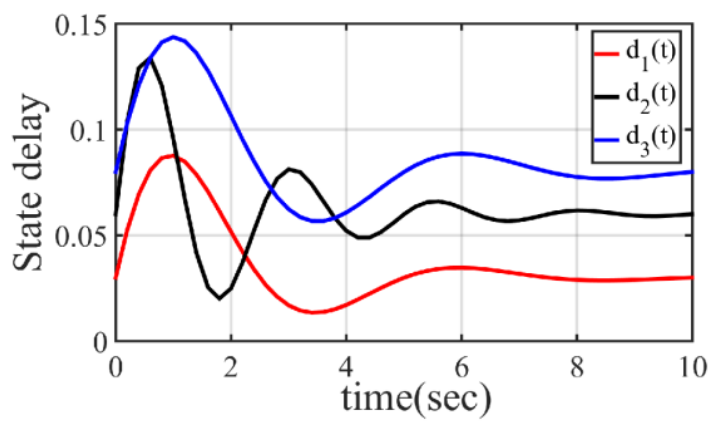

(a) $d_{i}(t)$

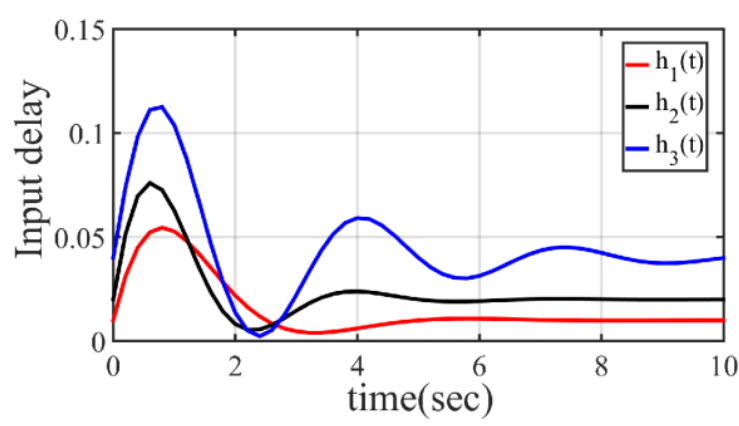

(b) $h_{i}(t)$

Figure 6. Time varying state and input delays

Scenario 1: The proposed design ensures finite time convergence of frequency and tie line power deviation with chattering free control signal under step load disturbance (see figs. 7(a), (b) \& (c)). The disturbance observer estimates the disturbance over wide range and ensures frequency deviations under load disturbance to be within acceptable limit 
(see fig. 7(d)). From the simulation results it can be seen that the oscillations in the response due to the presence of time delays perishes out in finite time.

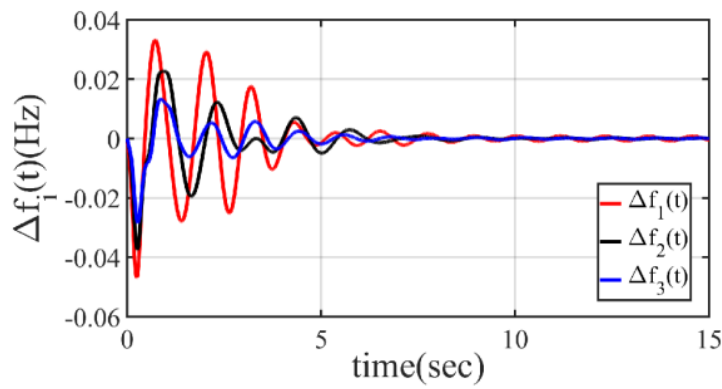

(a) $\Delta f_{i}(t)$

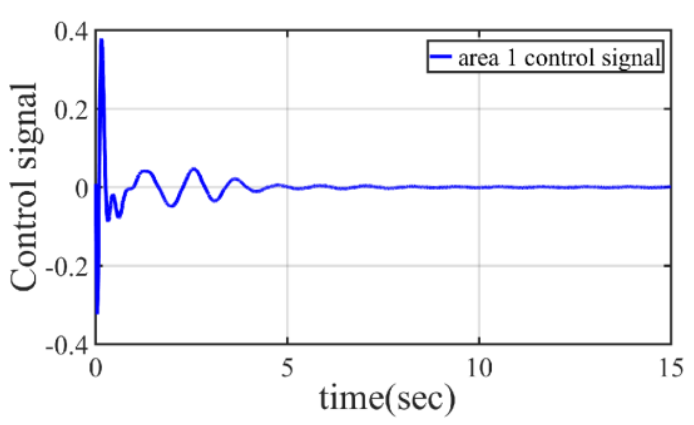

(c) Control signal

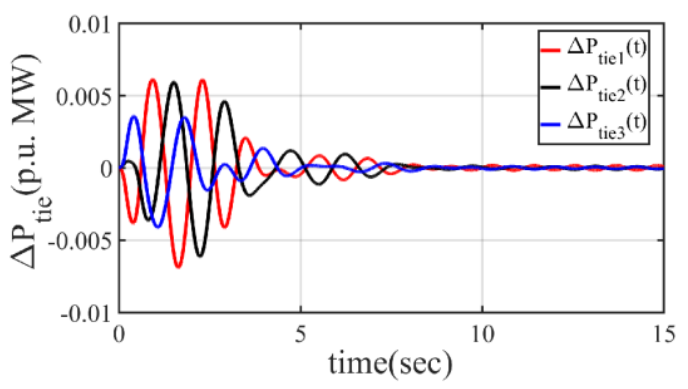

(b) $\Delta P_{\text {tie }_{i}}(t)$

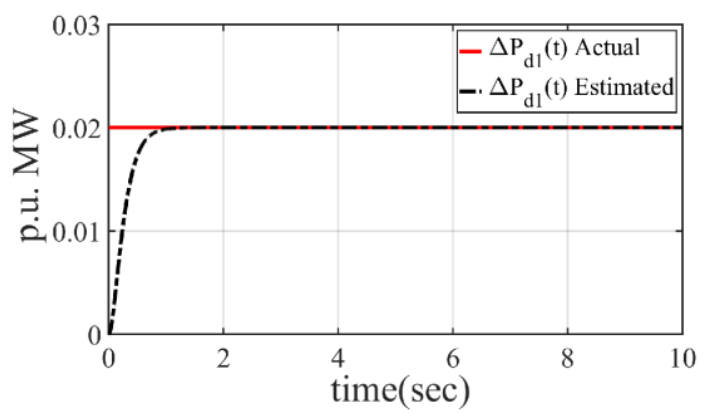

(d) Estimated disturbance

Figure 7. Response using proposed design under step load disturbance

Furthermore, the proposed design is also validated under disturbance which is combination of ramp signals. A ramp disturbance is considered till $t=1.5$ seconds and $t=1$ second in area 1 and 3 respectively. Further, there is a slope change in the disturbance at $t=1.5$ seconds and $t=1$ second in area 1 and 3 respectively. In area 2, no load disturbance is considered till $t<10$ seconds. At 10 seconds, there is a step load disturbance of 0.01 p.u. MW. The disturbances, estimated disturbances and corresponding frequency deviations can be seen from figs. 8(a) \& (b). From the simulation results, it can be observed that frequency deviations though affected by oscillations are found to be within acceptable limit under ramp disturbances.

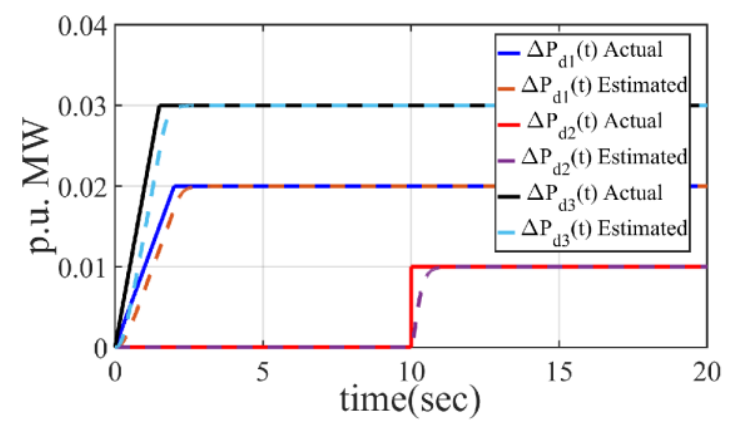

(a) $\Delta P_{d_{i}}(t)$ and $\Delta \hat{P}_{d_{i}}(t)$

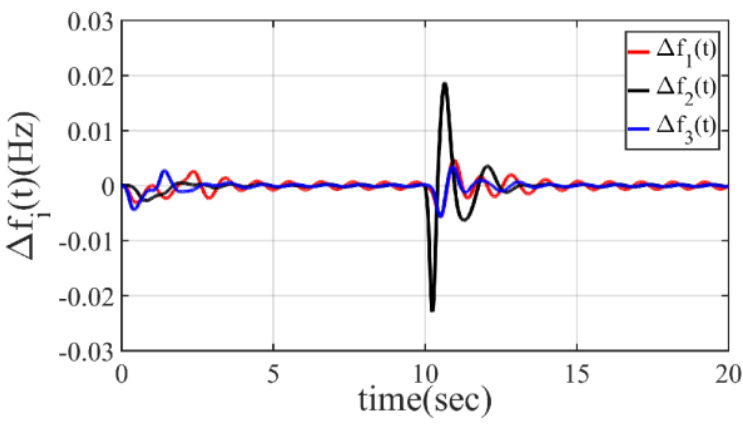

(b) $\Delta f_{i}(t)$

Figure 8. Response using proposed design under ramp disturbance 
Scenario 2: In order to test the robustness of the proposed control design, random step load disturbance is considered in each area. The random step load disturbance in area 1 , 2 and 3 is illustrated in figs. 9(a), 10(a) \& 11(a) respectively. The frequency deviations are found to within acceptable limit under random step load disturbance in the presence of time delays (see figs. 9(b), 10(b) \& 11(b)). This is achieved using chattering free control signal, furthermore the DO also gives a finite time estimation of random step load disturbance with minimum deviations (see figs. 12 (a) \& (b)).

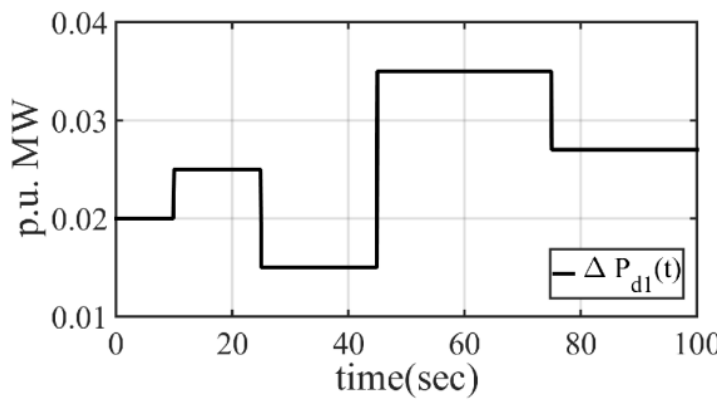

(a) $\Delta P_{d_{1}}(\mathrm{t})$

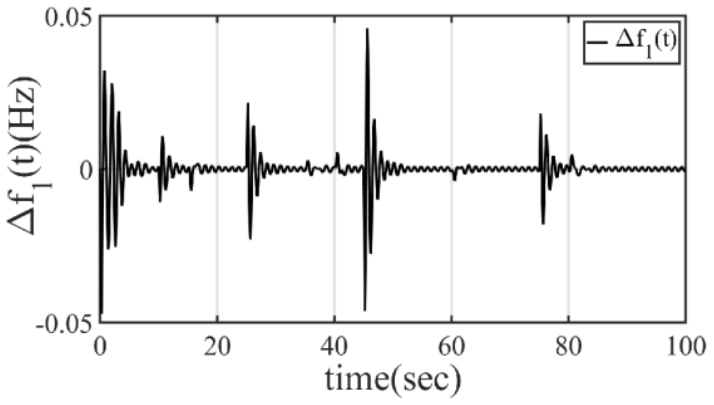

(b) $\Delta f_{1}(t)$

Figure 9. Response using proposed design under random step load disturbance

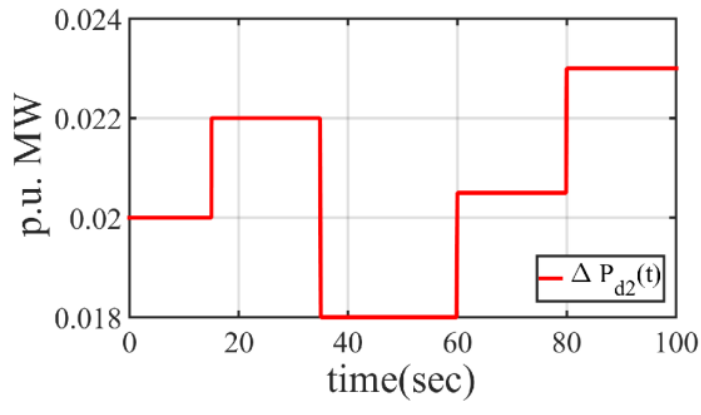

(a) $\Delta P_{d_{2}}(\mathrm{t})$

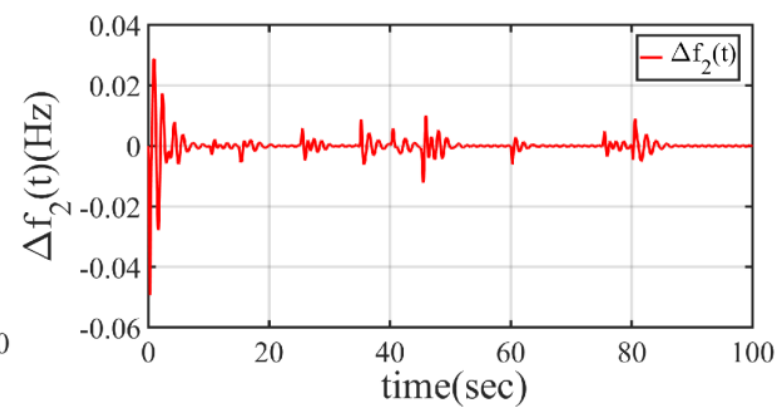

(b) $\Delta f_{2}(t)$

Figure 10. Response using proposed design under random step load disturbance

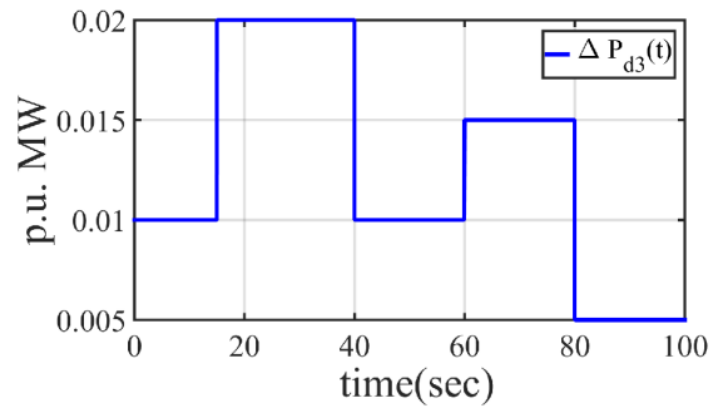

(a) $\Delta P_{d_{3}}$ (t)

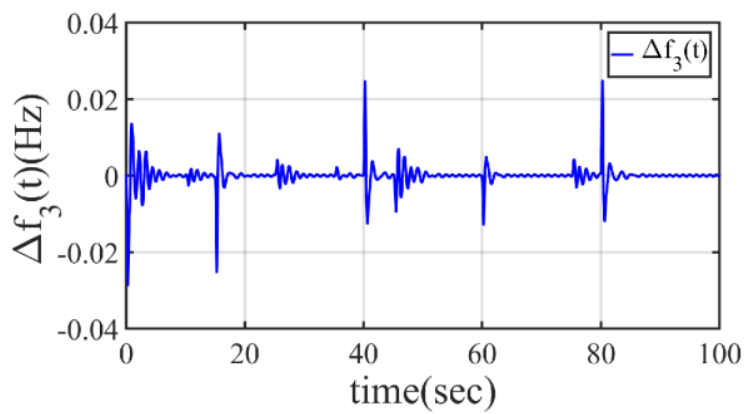

(b) $\Delta f_{3}(t)$

Figure 11. Response using proposed design under random step load disturbance 


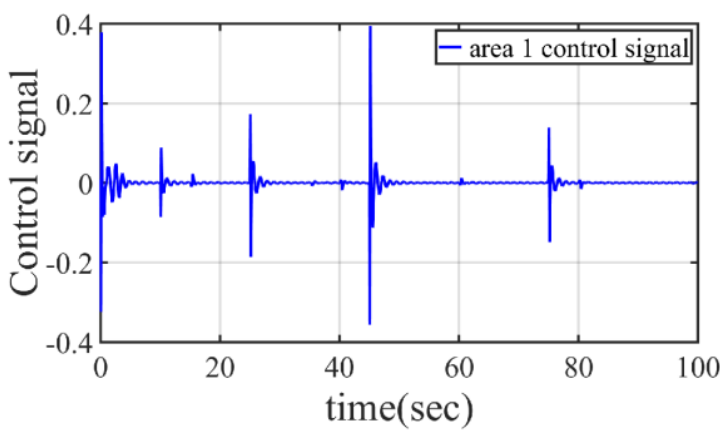

(a) Control signal

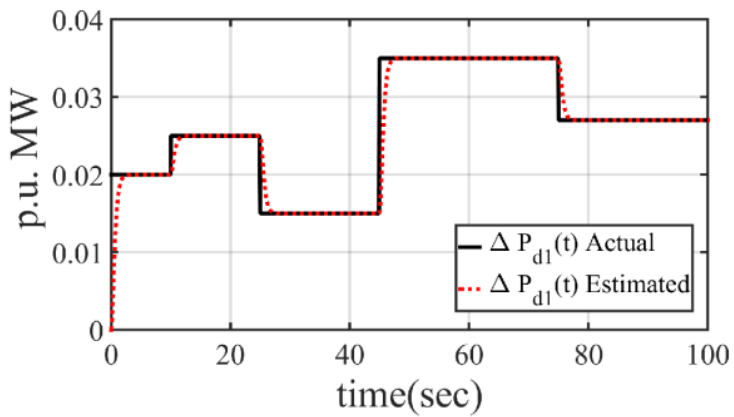

(b) Estimated disturbance

Figure 12. Response using proposed design under random step load disturbance

Scenario 3: In this case, constraints handling ability of the proposed design is validated in the presence of governor deadband (GDB) and generation rate constraints (GRC). A GRC is a physical constraint that limits the rate of change of generator output due to physical limitations of turbine. GDB can be defined as a band of input signal for which governor may not immediately react. In this case GRC is modelled using closed loop modelling method as shown in fig. 13(a) and can also be referred from Tan et al. (2017). The value of GDB and GRC considered are 0.0006 per unit or $0.06 \%$ and \pm 0.8 p.u. MW/sec respectively. From figs. 13(b), (c) \& (d) it can be observed that the dynamic performance of the proposed design is affected by larger overshoot due to the presence of nonlinearities. However, the proposed design still ensures a satisfactory performance in the presence of nonlinearities.

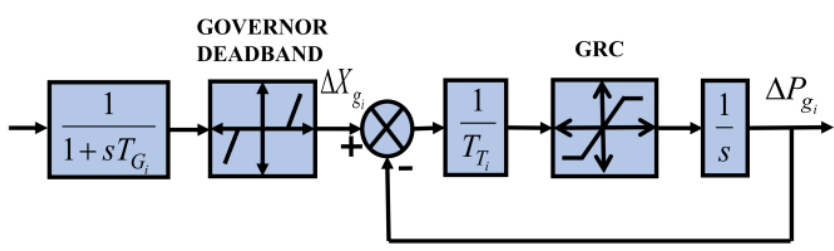

(a) Nonlinear model with GRC and GDB

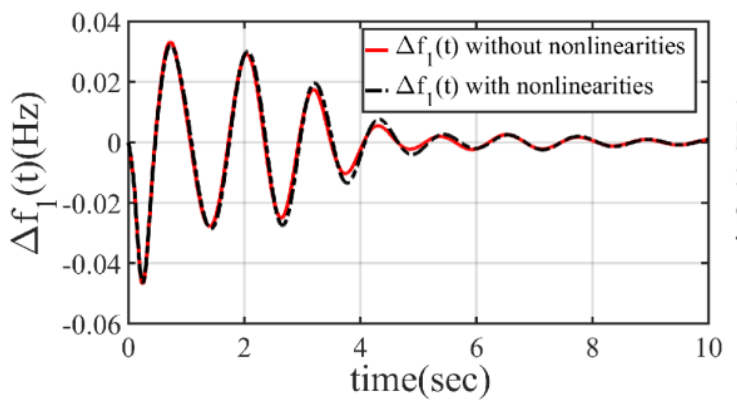

(b) $\Delta f_{1}(t)$

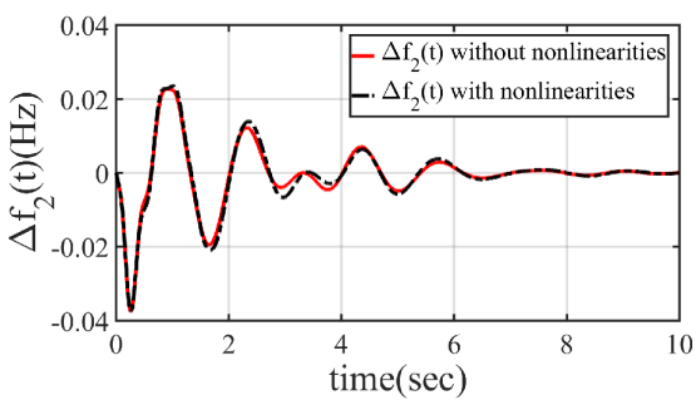

(c) $\Delta f_{2}(t)$ 


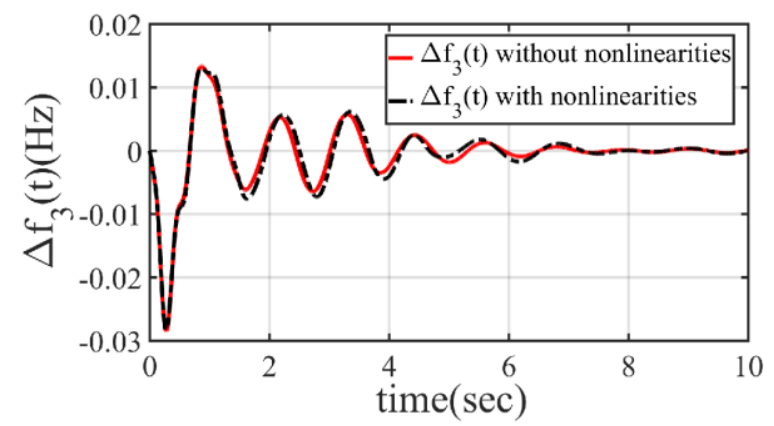

(d) $\Delta f_{3}(t)$

Figure 13. Response with nonlinearities under step load disturbance

Scenario 4: In this case, fluctuation in frequency is observed with the integration of renewable energy resources in particular wind energy. Wind energy is one of the cleanest, cheapest and eco-friendly resources of energy. However, wind power is usually dependent on the speed of the wind. Fluctuation in wind speed results in frequency deviation from its schedule value. The output of the wind turbine depends on the wind speed and is proportional to the cube of the wind speed (Mi et al., 2017). Neglecting nonlinearities in wind turbine system involving pitch control mechanism, the transfer function of wind turbine can be approximated by first-order lag function as in Lee and Wang (2008),

$$
G_{W}=\frac{\Delta P_{W G}}{\Delta P_{W}}=\frac{K_{W}}{1+s T_{W}}
$$

$\Delta P_{W G}$ is the change in wind energy output power, $\Delta P_{W}$ is the change in output power, $K_{W}$ is the gain of wind generator, $T_{W}$ is the time constant of wind generator. The values of the parameter can be referred from (Lee and Wang, 2008). The frequency deviation with the integration of renewable energy resource is found to be satisfactory and within acceptable limit (see figs. 14(a) \& (b)).

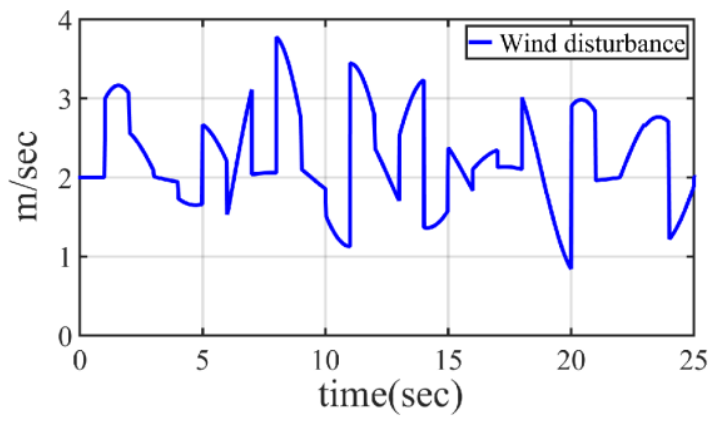

(a) Wind disturbance

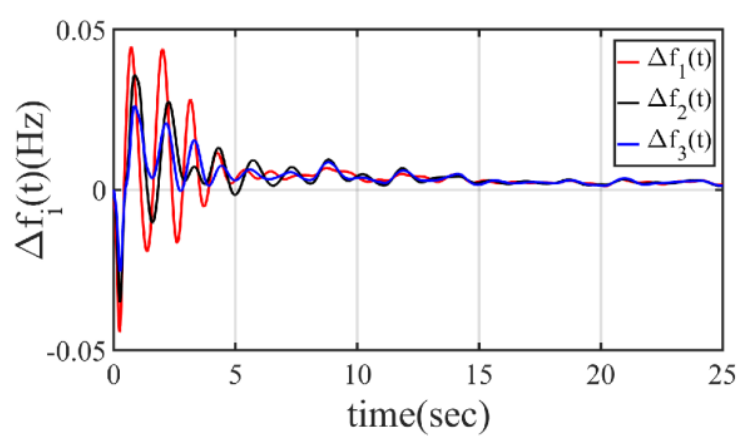

(b) $\Delta f_{i}(t)$

Figure 14. Response with an integration of wind energy under step load disturbance 
Scenario 5: In this case, the proposed method is validated with IEEE 39 bus large power system. It is a combination of 10 generators, 19 loads, 34 transmission lines and 12 transformers. The single line diagram of IEEE 39 bus system is illustrated in fig. 15(a). The 39-bus system can be sub grouped in 3 areas. Generators G1, G2 and G3 in area 1, Generators G8, G9 and G10 in area 2 and generators G4, G5, G6 and G7 are grouped in area 3 (Sarkar et al., 2018; Bevrani et al., 2010). However, only one generator in each area is responsible for load frequency task; generator G1, G9 and G4 in area 1, 2 and 3 respectively (Sarkar et al., 2018; Bevrani et al., 2010). The loads connected in area 1, area 2 and area 3 are 263 MW, 230 MW and 126 MW respectively. The other parameter values can be referred from Bevrani et al. (2010). The frequency deviation is affected by oscillations; however, the response is found to be satisfactory and within acceptable limit with IEEE 39 bus large power system (see fig. 15(b)).

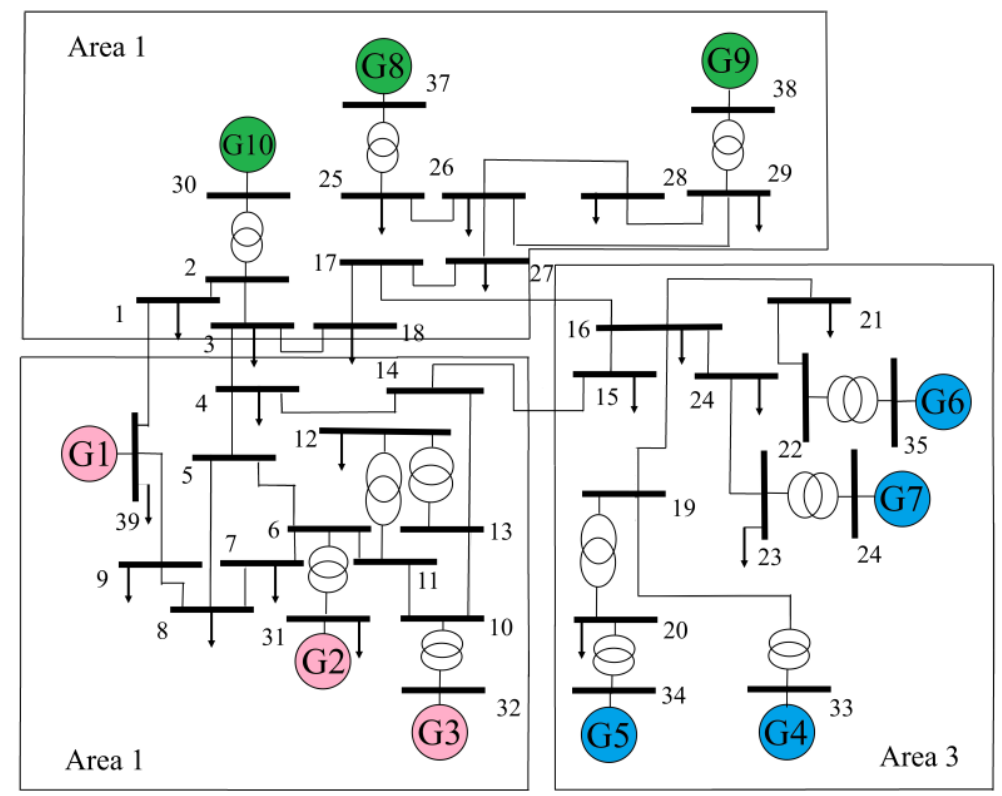

(a) Single line diagram of IEEE 39 bus system.

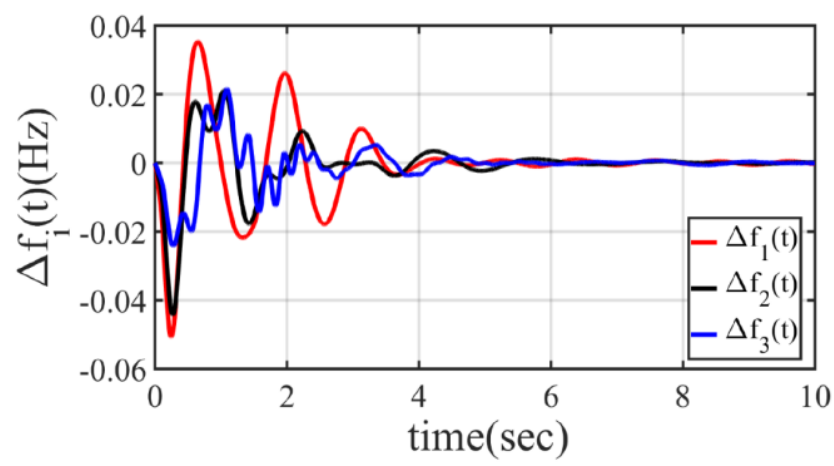

(b) $\Delta f_{i}(\mathrm{t})$

Figure 15. Response with IEEE 39 bus system under step load disturbance 


\section{Conclusion}

In this article, prediction-based ST-SMC with state and input time delays is reported. The proposed prediction-based control scheme is used to compensate the effects of time delays in the state and input loop. The design of STC is based on the estimated state and load disturbance. The design is carried out on three area interconnected power systems under step load disturbance, ramp and random step load disturbances, with power system nonlinearities, with an integration of renewable energy resource and also with IEEE 39 bus large power system. The system response: frequency and tie line power deviations have been evaluated and found to be within acceptable limits. This is achieved with chattering free control signal which is important during experimental implementations. Based on the present work, future work will focus LFC in the presence of multiple time delay. Control in the presence of multiple time delays is challenging and is still open for research.

\section{References}

Barragan H. C., Ibarra L, P, O., Loukianov A. G. and Plestan F. (2018). Robust Control for Perturbed Linear Systems with Time-Varying Delay via Sliding Mode Control. In $15^{\text {th }}$ International Workshop on Variable Structure Systems (VSS), pp. 7-12, Graz, Austria.

Bevrani H., Daneshfar F. and Daneshmand R. (2010). Intelligent Power System Frequency Regulation Concerning the Integration of Wind Power Units in L. Wang et al. (Eds): Wind Power System. Springer-Verlag Berlin Heidelberg, pp. 407-437.

Chalanga A., Kamal S., Fridman L., Bandyopadhyay B. and Moreno J. A. (2016). Implementation of super twisting control: Super twisting and higher order sliding mode observer-based approach. IEEE Transaction on Industrial Electronics, 63 (6), pp. 3677-3685.

Fridman E. (2014). Tutorial on Lyapunov based methods for time delay systems. European Journal of Control, 20(6), pp. 271-283.

Fridman L., Shtessel Y., Edwards C. and Yan X. G. (2008). Higher order sliding mode observer for state estimation and input reconstruction in nonlinear systems. Int. J. of Robust and Nonlinear Control, 18(4-5), pp. 399-412.

Fridman L., Levant A. and Davila J. (2007). Observation of linear systems with unknown inputs via high-order sliding-modes. International Journal of System Sciences, 38(10), pp. 773-791. 
Fridman L., Levant A. and Davila J. (2006). Higher order sliding mode observer for linear system with unknown input. International Workshop on Variable Structure Systems, Alghero, Sardinia, Italy.

Heng C. T., Jamaludin Z., Hashim A. Y. B., Abdullah L. and Rafan N. A. (2017). Design of super twisting algorithm for chattering suppression in machine tools. International Journal of Control, Automation and Systems, 15(3), pp. 1259-1266.

Jiang L., Yao W., Wu Q. H., Wen J. Y. and Cheng S. J. (2012). Delay dependent stability for load frequency control with constant and time varying delays. IEEE Transaction on Power Systems, 27(2), pp. 932-941.

Lee D. and Wang L. (2008). Small-Signal Stability Analysis of an Autonomous Hybrid Renewable Energy Power Generation/Energy Storage System Part I: Time Domain Simulations. IEEE Transaction on Energy Conversion, 23(1), pp. 311320.

Lechappe V., Moulay E. and Plestan F. (2018). Prediction based control for LTI systems with uncertain time varying delays and partial state knowledge. International Journal of Control, 91(6), pp. 1403-1414.

Lechappe V., Rouquet S., Gonzalez A., Plestan F., Leon J. D., Moulay E. and Glumineau A. (2016). Delay estimation and predictive control of uncertain systems with input delay: application to a DC motor. IEEE Transaction on Industrial Electronics, 63 (9), pp. 5849-5857.

Lechappe V., Moulay E., Plestan F., Glumineau A. and Chriette A. (2015). New predictive scheme for the control of LTI systems with input delay and unknown disturbances. Automatica, 52, pp. 179-184.

Liao K. and Xu Y. (2017). A robust load frequency control scheme for power systems based on second order sliding mode and extended disturbance observer. IEEE Transaction on Industrial Electronics, 14(7), pp. 3076-3086.

Li S., Yang J., Chen W. H. and Chen X. (2014). Disturbance Observer Based ControlMethods and Applications. CRC Press, Taylor \& Francis Group, ISBN: 13-9784665-1580-2.

Li J., Liu X. and Su X. (2018). Sliding mode observer-based load frequency control of multi area power systems under delayed inputs attack. In $30^{\text {th }}$ Chinese Control and Decision Conference, pp. 3716-3720, Shenyang, China. 
Liu J., Gao Y., Su X., Wack M. and Wu L. (2018). Disturbance-Observer-Based Control for Air Management of PEM Fuel Cells Systems via Sliding Mode Technique. IEEE Transaction on Control Systems Technology, 27(3), pp. 1129-1138.

Loukianov A. G., Barragan H. C., Ibarra L. O., Guerra O. E. and Toledo B. C. (2017). Robust control for uncertain linear delay systems via sliding mode control. International Journal of Robust and Nonlinear Control, 27(18), pp. 4825-4845.

Mi Y., Hao X., Liu Y., Fu Y., Wang C., Wang P. and Loh P. C. (2017). Sliding mode load frequency control for multi area time delay power system with wind power integration. IET Gen. Trans. Dist., 11(18), pp. 4644-4653.

Mi Y., Wang C. and Wang P. (2013). Decentralized sliding mode load frequency control for multi area power systems. IEEE Transaction on Power Systems, 28(4), pp. 4301-4309.

Mohamed M., Yan X. G., Spurgeon S. and Jiang B. (2016). Robust sliding mode observer design for interconnected systems. In $55^{\text {th }}$ Conference on Decision and Control, pp. 6246-6251, Las Vegas, USA.

Pandey S. K., Mohanty S. R. and Kishor N. (2013). A literature survey on load-frequency control for conventional and distribution generation power systems. Elsevier Renew. Sust. Energy Rev., 25, pp. 318-334.

Pappachen A. and Fathima A. P. (2017). Critical research area on load frequency control issues in a deregulated power system: A state-of-the-art-of-review. Elsevier Renew. Sust. Energy Rev., 72, pp. 163-177.

Pinto H. L. C. P., Oliveira T. R. and Hsu L. (2018a). Time-shift sliding mode predictor for fault reconstruction of time-delay systems using least square identification. In $15^{\text {th }}$ International Workshop on Variable Structure Systems (VSS), pp. 108-113, Graz, Austria.

Pinto H. L. C. P., Oliveira T. R., Hsu L. and Krstic M. (2018b). Sliding mode control for disturbance rejection in systems with measurement delay using PDE backstepping predictor. In $36^{\text {th }}$ Annual American Control Conference (ACC), pp. 4099-4104, Milwaukee, USA.

Prasad S., Purwar S. and Kishor N. (2017). Non-linear sliding mode load frequency control in multi-area power system. Control Engineering Practice, 61, pp. 81-92.

Prasad S. Purwar S. and Kishore N. (2016). H-infinity based nonlinear sliding mode controller for frequency regulation in interconnected power systems with constant 
and time-varying delays. IET Generation Transmission and Distribution, 10(11), pp. 2271-2784.

Sarkar M. K., Dev A., Asthana P. and Narzary D. (2017). Chattering free robust adaptive integral higher order sliding mode control for load frequency problems in multi area power systems. IET Control Theory Appl., 12(9), pp. 1216-1227.

Sargolzaei A., Yen K. K. and Abdelghani M. N. (2016). Preventing time delay switch attacks on load frequency control in distributed power systems. IEEE Transaction on Smart Grid, 7(2), pp. 1176-1185.

Seuret A. and Gouaisbaut F. (2018). Stability of linear systems with time varying delays using Bessel-Legendre inequalities. IEEE Transaction on Automatic Control, 63(1), pp. 225-232.

Singh V. P., Kishore N. and Samuel P. (2016). Communication time delay estimation for load frequency control in two area power system. Ad Hoc Networks, 41(1), pp. $69-85$.

Sun Y., Wang Y., Wei Z., Sun G. and Wu X. (2018). Robust $H_{\infty}$ load frequency control of multi area power system with time delay: A sliding mode control approach. IEEE/CAA Journal of Automatica Sinica, 5(2), pp. 610-617.

Tan W., Chang S. and Zhou R. (2017). Load frequency control of power systems with non-linearities. IET Gen. Trans. Dist., 11(11), pp. 4307-4313.

Wang C., Mi Y., Fu Y. and Wang P. (2018). Frequency control of an isolated micro grid using double sliding mode controller and disturbance observer. IEEE Transaction on Smart Grid, 9(2), pp. 1308-1317.

Wen S., Yu X., Zeng Z. and Wang J. (2015). Event-triggered load frequency control for multi area power system with communication delays. IEEE Transaction on Industrial Electronics, 63(2), pp. 923-930.

Wu M., He Y. and She J. H. (2010). Stability analysis and robust control of time delay systems. Springer.

Yan H., Zhou X., Zhang H., Yang F. and Wu Z. G. (2017). A novel sliding mode estimation for microgrid control with communication time delay. IEEE Transaction on Smart Grid, 10(2), pp. 1509-1520.

Yang F., He J. and Pan Q. (2018). Further improvement on delay dependent load frequency control of power systems via truncated B-L inequality. IEEE Transaction on Power Systems, 33(5), pp. 5062-5071. 
Zhang C. K., Jiang L., Wu Q. H., He Y. and Wu M. (2013). Delay dependent robust load frequency control for time delay power systems. IEEE Transaction on Power Systems, 28(3), pp. 2192-2201.

Zhong Q. C. (2006). Robust control of time delay systems. Springer. 